\title{
Doppler Lidar Investigations of Wind Turbine Near-Wakes and LES Modeling with New Porous Disc Approach
}

\author{
Takanori Uchida ${ }^{1, *(1)}$, Tadasuke Yoshida ${ }^{2}$, Masaki Inui ${ }^{2}$ and Yoshihiro Taniyama ${ }^{3}$ \\ 1 Research Institute for Applied Mechanics (RIAM), Kyushu University, 6-1 Kasuga-kouen, Kasuga, \\ Fukuoka 816-8580, Japan \\ 2 Wind Power Business Unit, Engineering and Technology Development Department, Hitachi Zosen \\ Corporation, 7-89 Nanko-Kita 1-chome, Suminoe-ku, Osaka 559-8559, Japan; \\ ta_yoshida@hitachizosen.co.jp (T.Y.); inui_m@hitachizosen.co.jp (M.I.) \\ 3 Energy Systems Research and Development Center, Mechanical Engineering R\&D Department, Vibration \\ Technology Group, Toshiba Energy Systems \& Solutions Corporation, 2-4 Suehiro-cho, Tsurumi-ku \\ Yokohama-shi, Kanagawa 230-0045, Japan; yoshihiro.taniyama@toshiba.co.jp \\ * Correspondence: takanori@riam.kyushu-u.ac.jp; Tel.: +81-92-583-7776; Fax: +81-92-583-7779
}

check for updates

Citation: Uchida, T.; Yoshida, T.; Inui, M.; Taniyama, Y. Doppler Lidar Investigations of Wind Turbine Near-Wakes and LES Modeling with New Porous Disc Approach. Energies 2021, 14, 2101. https://doi.org/ 10.3390/en14082101

Academic Editor: Riccardo Amirante

Received: 15 February 2021

Accepted: 7 April 2021

Published: 9 April 2021

Publisher's Note: MDPI stays neutral with regard to jurisdictional claims in published maps and institutional affiliations.

Copyright: (C) 2021 by the authors Licensee MDPI, Basel, Switzerland. This article is an open access article distributed under the terms and conditions of the Creative Commons Attribution (CC BY) license (https:// creativecommons.org/licenses/by/ $4.0 /)$.

\begin{abstract}
Many bottom-mounted offshore wind farms are currently planned for the coastal areas of Japan, in which wind speeds of 6.0-10.0 m/s are extremely common. The impact of such wind speeds is very relevant for the realization of bottom-mounted offshore wind farms. In evaluating the feasibility of these wind farms, therefore, strict evaluation at wind speeds of $6.0-10.0 \mathrm{~m} / \mathrm{s}$ is important. In the present study, the airflow characteristics of $2 \mathrm{MW}$-class downwind wind turbine wake flows were first investigated using a vertically profiling remote sensing wind measurement device (lidar). The wind turbines used in this study are installed at the point where the sea is just in front of the wind turbines. A ground-based continuous-wave (CW) conically scanning wind lidar system ("ZephIR ZX300") was used. Focusing on the wind turbine near-wakes, the detailed behaviors were considered. We found that the influence of the wind turbine wake, that is, the wake loss (wind velocity deficit), is extremely large in the wind speed range of $6.0-10.0 \mathrm{~m} / \mathrm{s}$, and that the wake loss was almost constant at such wind speeds $(6.0-10.0 \mathrm{~m} / \mathrm{s})$. It was additionally shown that these results correspond to the distribution of the thrust coefficient of the wind turbine. We proposed a computational fluid dynamics (CFD) porous disk (PD) wake model as an intermediate method between engineering wake models and CFD wake models. Based on the above observations, the wind speed range for reproducing the behavior of the wind turbine wakes with the CFD PD wake model we developed was set to $6.0-10.0 \mathrm{~m} / \mathrm{s}$. Targeting the vertical wind speed distribution in the near-wake region acquired in the "ZephIR ZX300", we tuned the parameters of the CFD PD wake model $\left(C_{R C}=2.5\right)$. We found that in practice, when evaluating the mean wind velocity deficit due to wind turbine wakes, applying the CFD PD wake model in the wind turbine swept area was very effective. That is, the CFD PD wake model can reproduce the mean average wind speed distribution in the wind turbine swept area.
\end{abstract}

Keywords: wind turbine near-wakes; Doppler lidar; large-eddy simulation (LES); CFD porous disk (PD) wake model

\section{Introduction}

Generally, as the blade of a wind turbine rotates, a velocity loss region is formed downstream of the turbine (see Figure 1). In a large-scale offshore wind farm, two major problems have been highlighted regarding the wind turbines located on the downstream side due to the wind turbine wakes located on the upstream side: (i) a decrease in the amount of power generated by the wind turbine located on the downstream side and (ii) the occurrence of failures inside the wind turbine nacelle and wind turbine blades. 
A review of the state-of-the-art in wind turbine wake modeling is organized in detail in the literature [1-3]. The literature also describes in detail various approaches to the behavior of wind turbine wakes [4-9]. The most common engineering wake model/analytical wake model for wind farms is the so-called Park wake model by Jensen [8] and Katic [9]. The Park wake model implements a simple formula for the size of the wake deficit and its expansion downstream with a single adjustable parameter (wake decay constant). Therefore, the Park wake model is still widely used for evaluating business feasibility in the wind industry in Japan and overseas. Engineering wake models are extremely difficult to accurately predict the mutual interference of wind turbine wakes.

We have already proposed the CFD PD wake mode [10]. In the present study, the validity of the CFD PD wake model was verified by the wake of a $2 \mathrm{MW}$-class downwind turbine. The airflow characteristics of $2 \mathrm{MW}$-class downwind wind turbine wake flows were first investigated using a vertically profiling remote sensing wind measurement device (lidar). The wind turbines used in this study are installed the point where the sea is just in front of the wind turbines. A ground-based CW conically scanning wind lidar system ("ZephIR ZX300") [11,12] was used for lidar. Particular attention was concentrated on the behavior of the wind turbine near-wakes. Next, targeting the near-wake flow characteristics acquired in the "ZephIR ZX300", we tuned the parameters of the wake model we proposed and considered the numerical results, including those of the conventional engineering wake models.

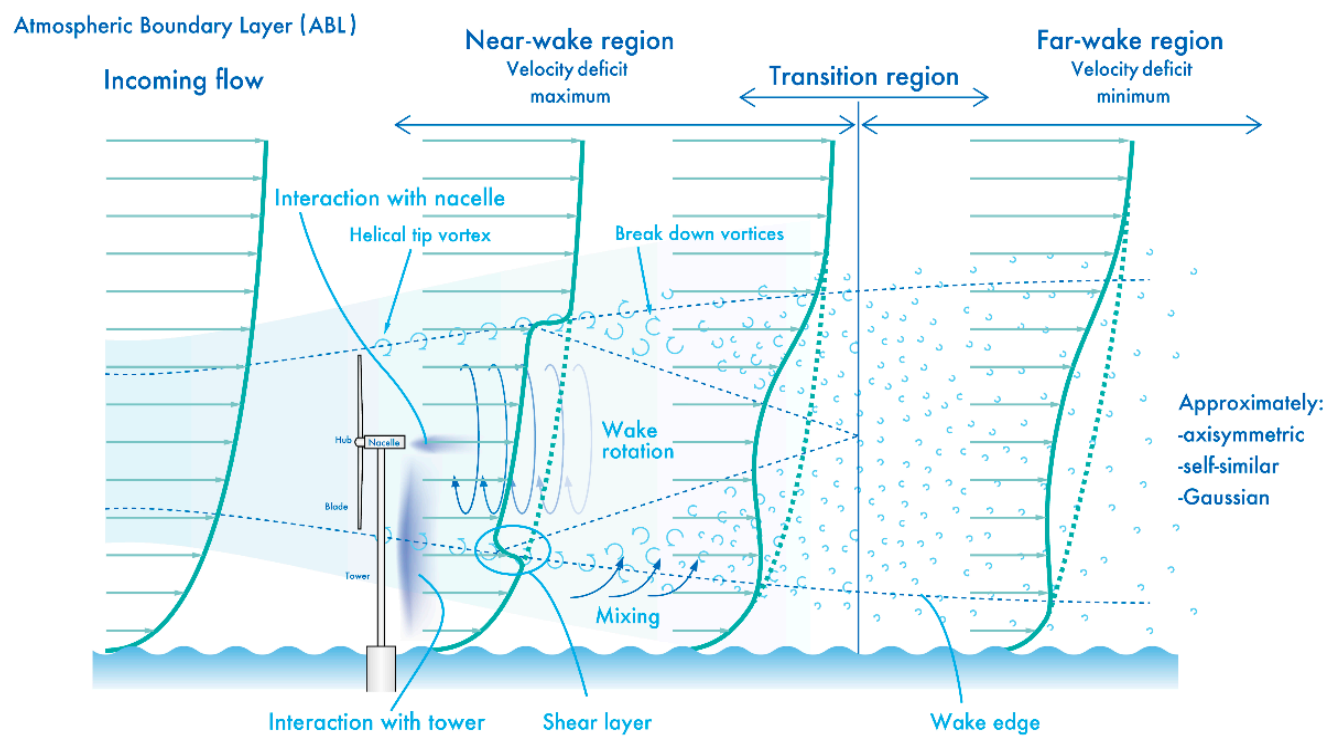

Figure 1. Schematic diagram of wind turbine wake structure.

\section{Wind Measurements of Wind Turbine Near-Wake by Doppler Lidar}

\subsection{Overview of Omonogawa Wind Power Station in Akita Prefecture}

The Omonogawa Wind Power Station, owned by Hitachi Zosen Corporation, is located on the north side of the mouth of the Omonogawa River in Akita City, Akita Prefecture, Japan. As shown in Figure 2, two downwind-type wind turbines with a rated output of 2-MW, manufactured by Hitachi, Ltd., are in operation: the first, since 1 March 2015 and the second, since 1 February 2016. As shown in Figure 2a, the separation distance between wind turbines No.1 and No. 2 is about $280 \mathrm{~m}$. Considering wind turbine No.2 as a reference, wind turbine No.1 is located about 3.3 D downstream of No.2, where D $(=86 \mathrm{~m})$ is the rotor diameter of No.2. The predominant wind direction in this area is west-northwest, and it is a major feature that the two wind turbines are arranged almost in a straight line. Furthermore, wind turbine No.2 is located about $80 \mathrm{~m}$ from the coastline. When a winter monsoon (main wind direction: west-northwest to northwest) occurs, the wind 
environment in this area is similar to the wind environment that would be found above the ocean. In this study, the wind field from the sea (sea breeze) was the subject of research.

Figure 3 shows the various aerodynamic characteristics of downwind wind turbines with a rated output of 2-MW targeted in this study. The wind speed at which the power coefficient shows the maximum value (about 0.48 ) is around $8.0 \mathrm{~m} / \mathrm{s}$, and the thrust coefficient corresponding to this is about 0.8 . In this study, we focused on the airflow characteristics of the wind turbine wake at $6.0-10.0 \mathrm{~m} / \mathrm{s}$.
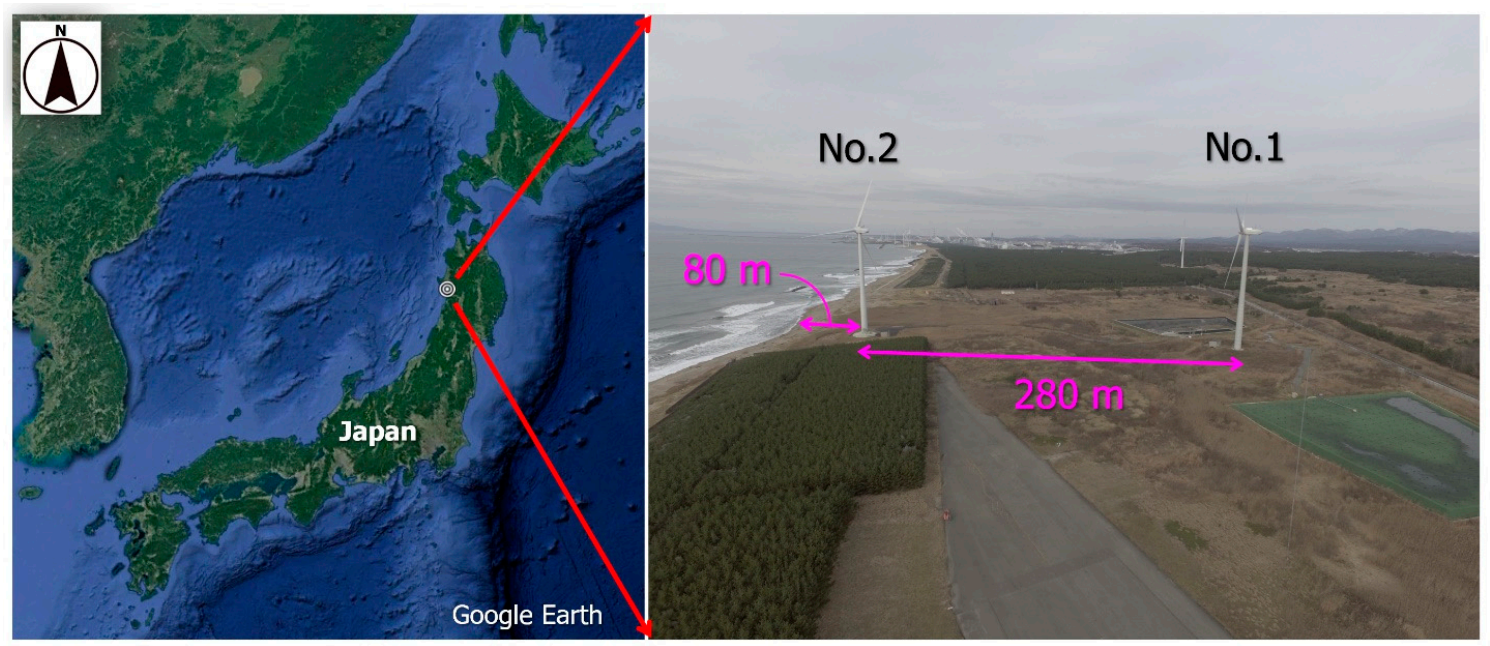

(a)

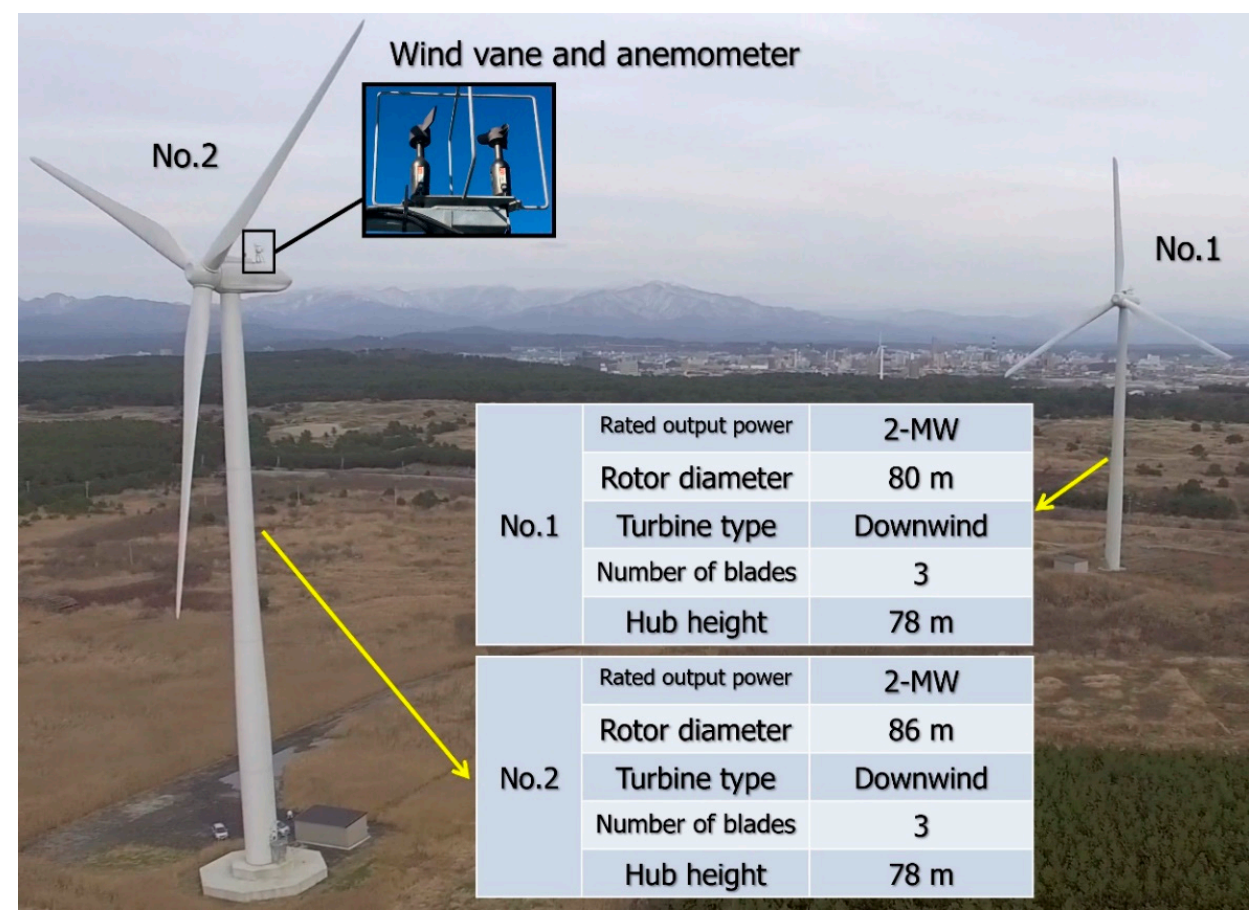

(b)

Figure 2. Omonogawa Wind Power Station targeted in this study. (a) Overall view; (b) enlarged view. 


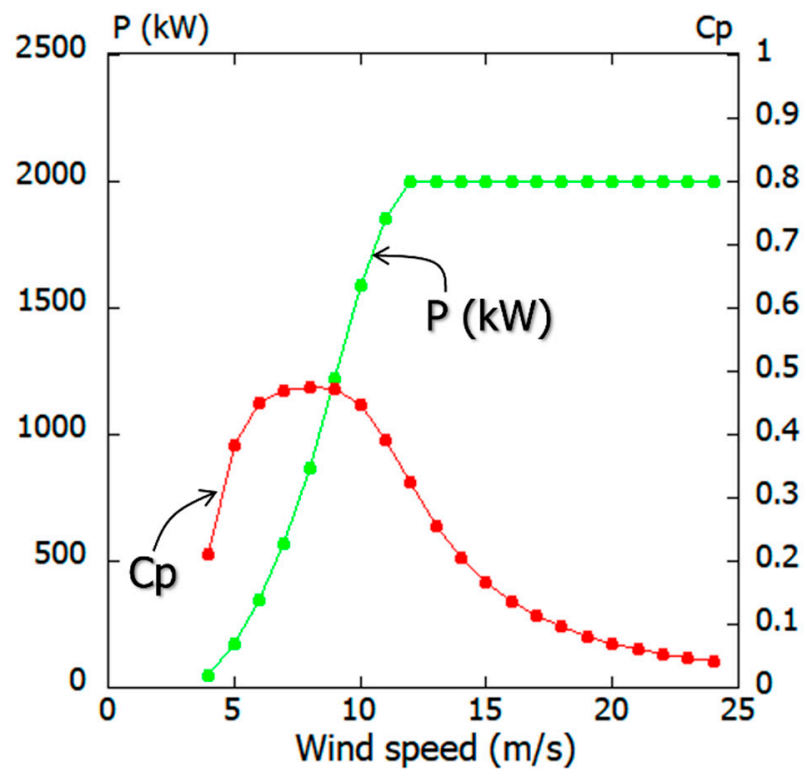

(a)

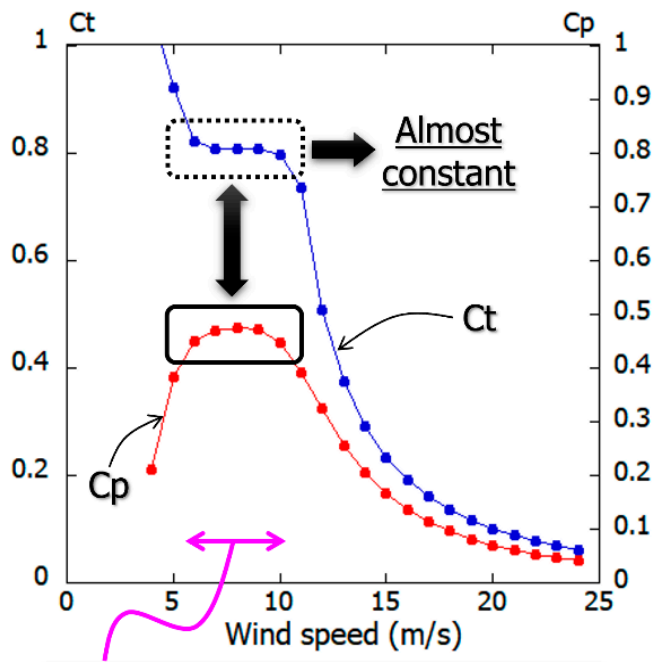

Wind speed range reproduced by CFD PD wake model

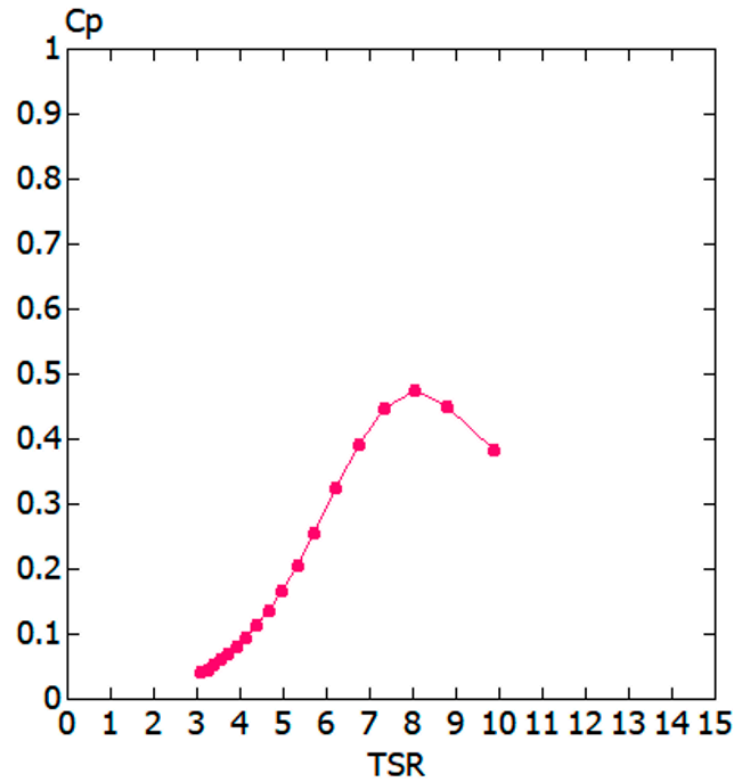

(b)

(c)

Figure 3. Various aerodynamic characteristics of downwind-type wind turbines with a rated output of 2-MW targeted in this study. (a) Generated power, P and power coefficient, Cp vs. wind speed; (b) thrust coefficient, Ct and power coefficient, Cp vs. wind speed; (c) power coefficient, Cp vs. tip speed ratio, TSR.

\subsection{Overview of Doppler Lidar Measurement}

Figure 4 shows the positional relationship between the two wind turbines, the Doppler lidar, and the wind measurement by the $50 \mathrm{~m}$ observation mast. In this study, a Britishmade Doppler lidar "ZephIR ZX300" was used. The "ZephIR ZX300" can measure a total of 10 points of wind direction, wind speed and turbulence intensity at any altitude from about $40 \mathrm{~m}$ to about $200 \mathrm{~m}$. 


\section{Wind direction that carried out the Doppler lidar investigation of wind turbine wake characteristics}

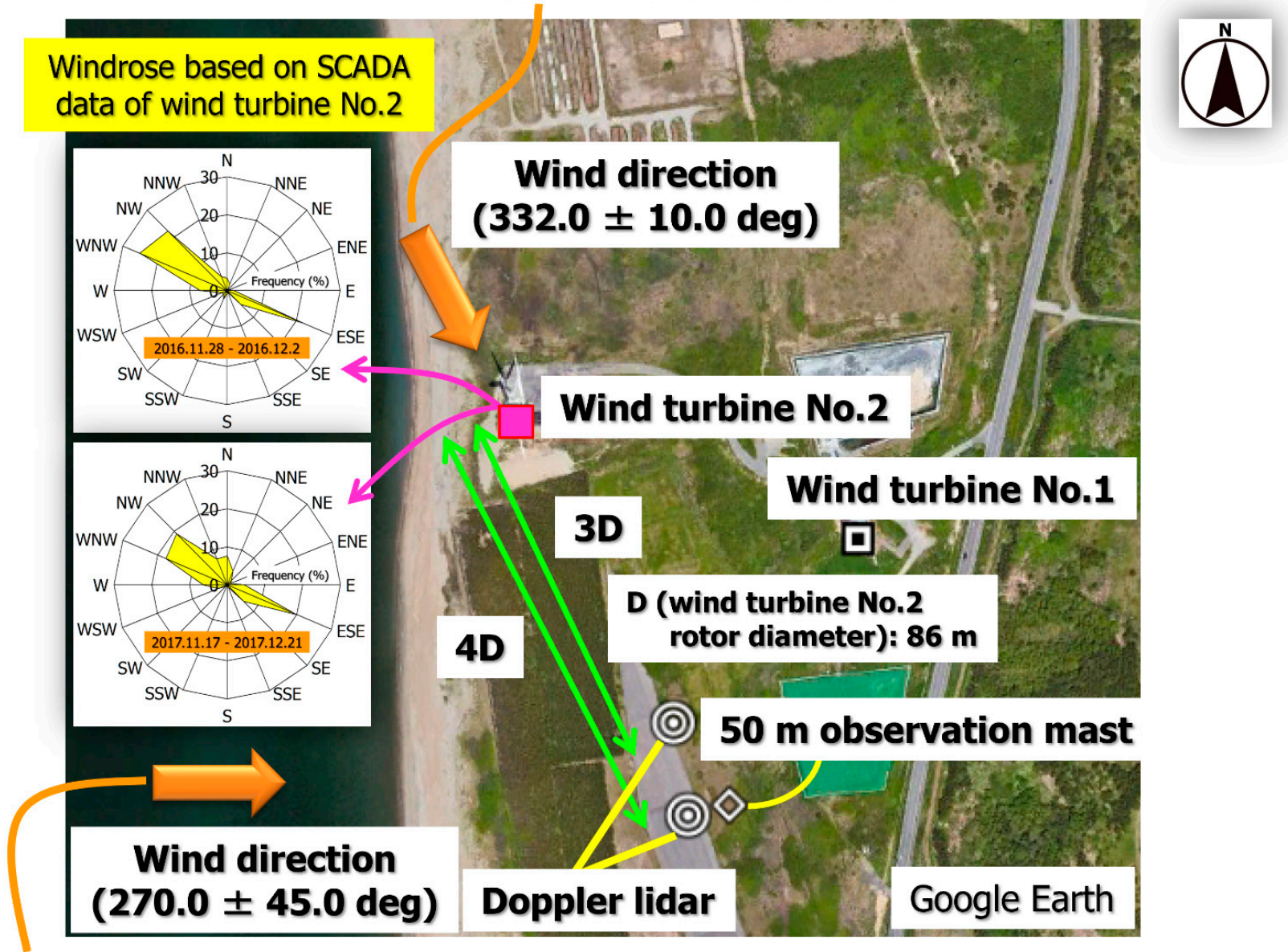

\section{Wind direction that verified the accuracy of the Doppler lidar measurement}

Figure 4. Positional relationship between wind turbines and wind measurement devices in this study including windrose plot. Measurement period: 28 November 2016-2 December 2016 and 17 November 2017-21 December 2017.

\subsection{Verification of Accuracy of Doppler Lidar Measurement}

First, we verified the accuracy of the Doppler lidar measurement. As shown in Figure 4, the Doppler lidar system was installed downstream of wind turbine No.2 at 3D and $4 \mathrm{D}$, where $\mathrm{D}(=86 \mathrm{~m})$ means the rotor diameter of the wind turbine No.2. All the measurement data shown below were 10-minutes mean statistics.

Figure 5 shows the situation when the Doppler lidar is installed at 3D and 4D distance from wind turbine No.2. Only plants are present between the wind turbine and the Doppler lidar, as shown in Figure 5a.

In the case where the Doppler lidar system was installed downstream of wind turbine No.2 at 3D, we compared the nacelle-measured wind speed and turbulence intensity of turbine No.2 with the wind speed and turbulence intensity by the Doppler lidar for the westerly wind $(270.0 \pm 45.0 \mathrm{deg})$, which is not affected by the wind turbine wakes (see Figure 4$)$. The hub height $(78 \mathrm{~m})$ of wind turbine No.2 was considered as the reference altitude. Considering the balance of measurement points, 46, 57, 78, 88, 98, 108, 118, 120, 128, 138 and $207 \mathrm{~m}$ were set as the measurement points.

On the other hand, in the case where the Doppler lidar system was installed downstream of wind turbine No.2 at 4D, we also compared the $50 \mathrm{~m}$ observation mast data and the Doppler lidar data with respect to the above wind direction $(270.0 \pm 45.0 \mathrm{deg})$. The $50 \mathrm{~m}$ observation mast was considered as the reference altitude. Considering the balance 
of measurement points, 39, 50, 71, 81, 91, 101, 111, 113, 121, 131 and $200 \mathrm{~m}$ were set as the measurement points.

Figure 6 shows the verification results of the accuracy of the Doppler lidar measurement. In this study, the comparison of wind speed and turbulence intensity were performed. As shown in Figure 6a (that is, correlation between the measurements made by the nacelle-mounted wind vane and anemometer and by the Doppler lidar for the wind speed and turbulence intensity), no clear correlation was found for the turbulence intensity due to the influence of the nacelle (correlation coefficient $R=0.59$, coefficient of determination $\mathrm{R}^{2}=0.35$ ). On the other hand, a good correlation was confirmed for the wind speed $\left(R=0.98, R^{2}=0.96\right)$. On the other hand, in comparison with the $50 \mathrm{~m}$ observation mast shown in Figure $6 \mathrm{~b}$ (that is, correlation between the measurements made by the $50 \mathrm{~m}$ observation mast and by the Doppler lidar for the wind speed and turbulence intensity), it was confirmed that there is a very high correlation between the wind speed $\left(\mathrm{R}=0.99, \mathrm{R}^{2}=0.98\right)$ and the turbulence intensity $\left(\mathrm{R}=0.94, \mathrm{R}^{2}=0.88\right)$. Therefore, the Doppler lidar "ZephIR ZX300" was found suitable to measure the wind speed and the turbulence intensity.

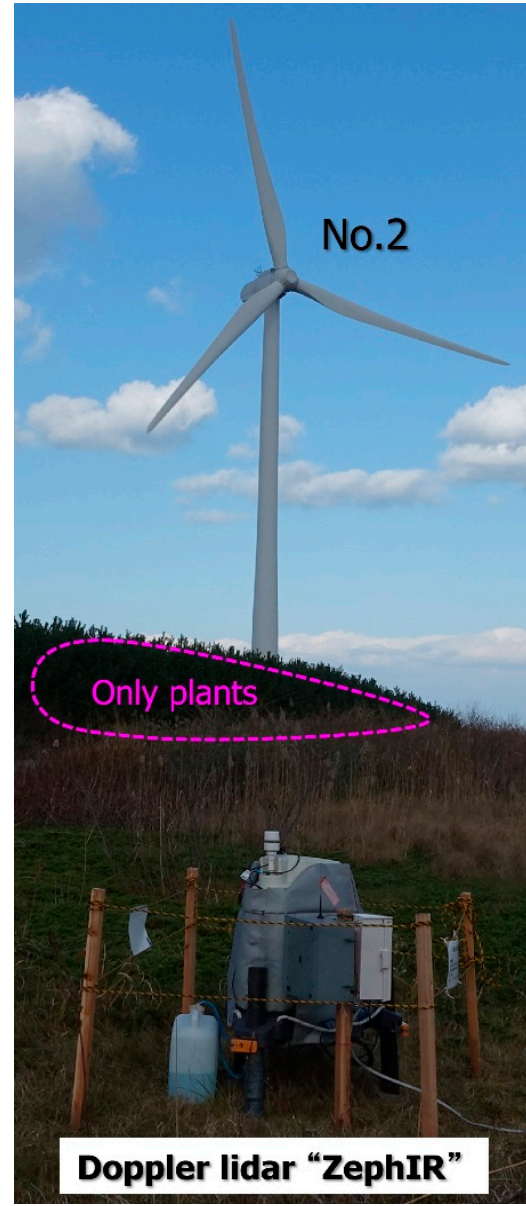

(a)

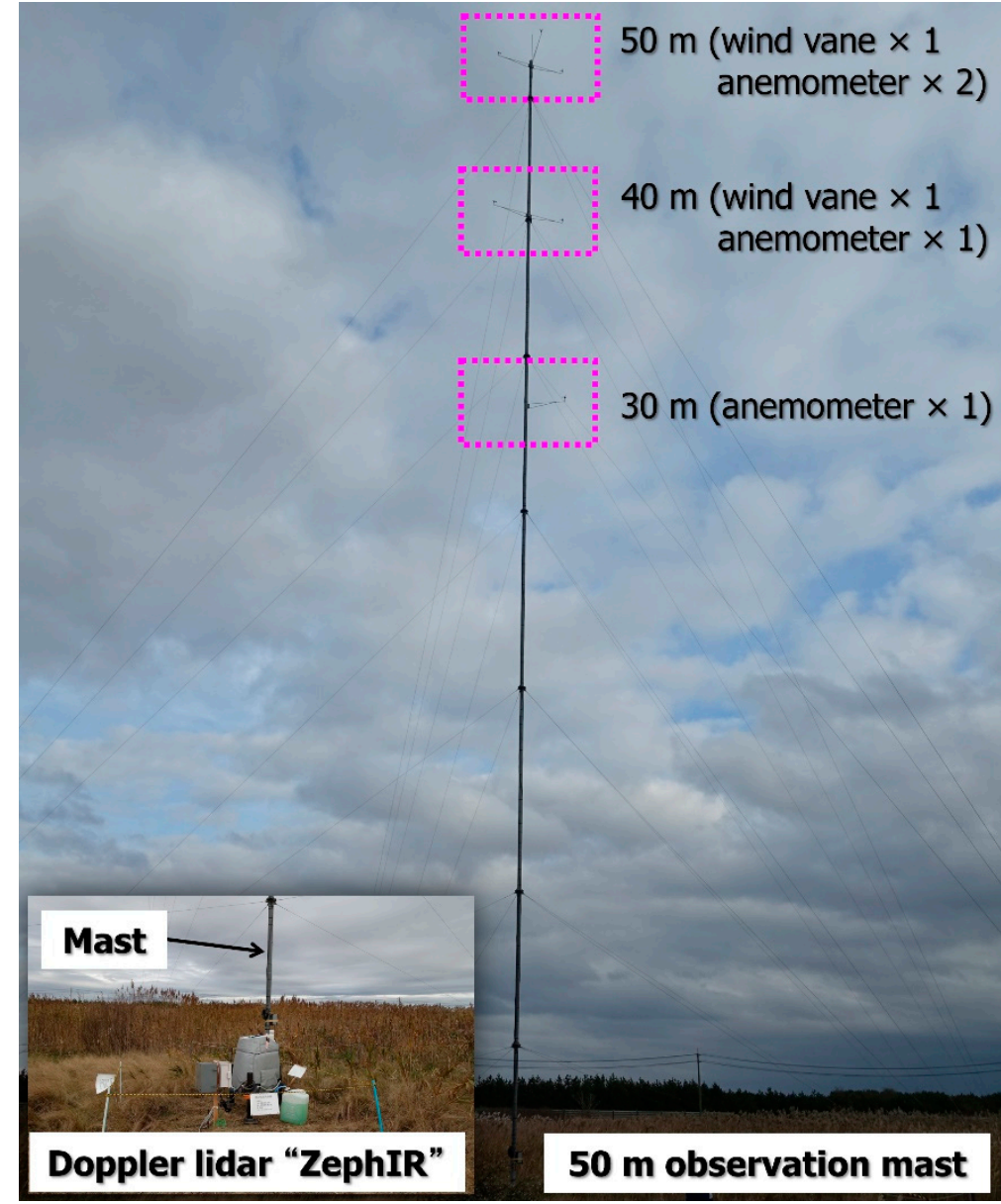

(b)

Figure 5. Installation status of Doppler lidar. (a) 3D distance from wind turbine No.2; (b) 4D distance from wind turbine No.2 $(\mathrm{D}=86 \mathrm{~m})$. 

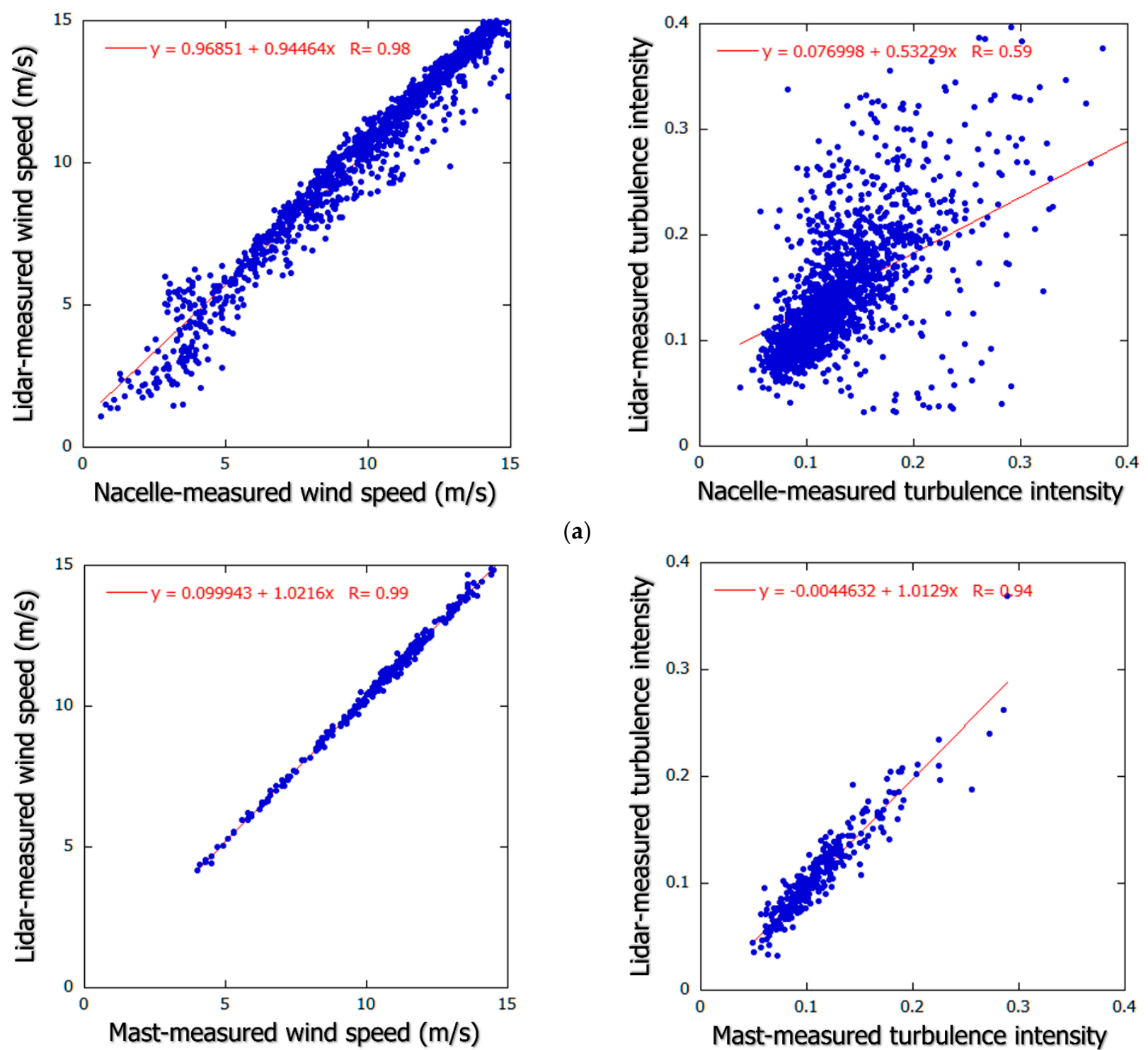

(a)

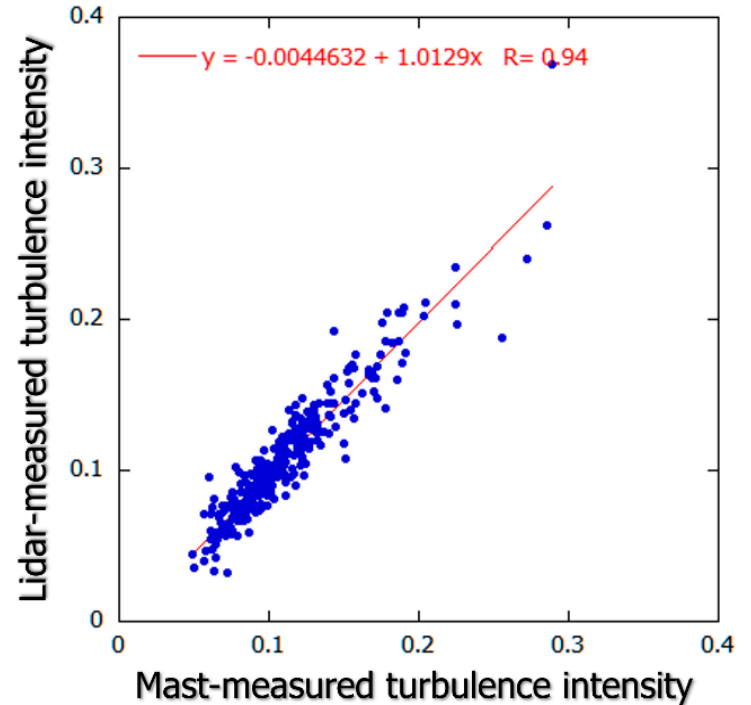

(b)

Figure 6. Verification results of accuracy of Doppler lidar measurement; left: wind speed, right: turbulent intensity. (a) Comparison of nacelle (78 $\mathrm{m}$ above ground) and Doppler lidar, measurement period: 17 November 2017-21 December 2017; (b) comparison of observation mast (50 m above ground) and Doppler lidar, measurement period: 11 November 2016-28 November 2016.

\subsection{Doppler Lidar Investigation of Wind Turbine Near-Wakes and Consideration}

The main purpose of this study was to understand the airflow characteristics of the wind turbine near-wake in a pseudo-offshore environment. We focused on the period in which the monsoon is generated from the sea in winter (28 November 2016-2 December 2016 and 17 November 2017-21 December 2017), the Doppler lidar "ZephIR ZX300" was installed downstream of wind turbine No.2 at 3D $(\mathrm{D}=86 \mathrm{~m})$. As shown in Figure 4, we analyzed the measured data with a wind direction of $332.0 \pm 10.0 \mathrm{deg}$ (prevailing wind direction at this time), and all outliers and missing values were removed.

Figure 7 shows the vertical distribution of the mean wind speed downstream of wind turbine No.2 at 3D $(\mathrm{D}=86 \mathrm{~m})$; in this figure, the results are organized in increments of $1 \mathrm{~m} / \mathrm{s}$ (see Table 1) and the data are averaged at each altitude. For the wind speed shown in Table 1, the nacelle-measured wind speed was corrected with the Doppler lidar output at the hub height $(78 \mathrm{~m})$ of wind turbine No.2 as the true value. Furthermore, for example, for a wind speed of $5 \mathrm{~m} / \mathrm{s}$, alle wind speeds in the range of $5.00 \mathrm{~m} / \mathrm{s}$ to $5.99 \mathrm{~m} / \mathrm{s}$ were 
counted. Figure 7 reveals that there is a clear difference in the formation of wind turbine wakes at each wind speed. That is, there is a significant deficit in each wind speed due to wind turbine wakes. Considering this together with Figure 3, it can be seen that at wind speeds of about $8.0-9.0 \mathrm{~m} / \mathrm{s}$, where the power coefficient is maximized, the amount of wake loss near the height of the wind turbine hub (78 $\mathrm{m}$ above the ground) is extremely large compared to the other wind speed classes. The main reasons for this are as follows: at wind speeds of about $8.0-9.0 \mathrm{~m} / \mathrm{s}$, the wind turbine operates most efficiently in obtaining wind energy, so the amount of wake loss (wind velocity deficit) is considered to be large. When the wind speed is about $10.0 \mathrm{~m} / \mathrm{s}$ or more, the amount of wake loss near the height of the wind turbine hub (78 $\mathrm{m}$ above the ground) gradually decreases as the wind speed increases. We consider that this is because the pitch angle is controlled so that the wind turbine blade does not become a source of resistance to the wind (so-called pitch angle control).

Wake loss was clearly confirmed in the wind speed range of $6.0-10.0 \mathrm{~m} / \mathrm{s}$ (Figure 7); Figure 8 shows the results for this wind speed range normalized by the wind speed near the wind turbine hub height (ground clearance of $78 \mathrm{~m}$ ). It should be noted that the measurement results for wind speeds of $6.0-10.0 \mathrm{~m} / \mathrm{s}$ in Figure 8 have almost the same vertical distribution in the range of the wind turbine swept area $(\mathrm{z}=35-121 \mathrm{~m})$; in this range, there is no significant difference in the amount of wake loss regardless of the wind speed. This tendency corresponds to the distribution of the thrust coefficient of the wind turbine shown in Figure 3b. Based on these results, in this study, the wind speed range targeted by the CFD PD wake model was set to $6.0-10.0 \mathrm{~m} / \mathrm{s}$ (see Figure $3 \mathrm{~b}$ ).

Figure 9a shows the vertical distribution of the turbulence intensity at $3 \mathrm{D}(\mathrm{D}=86 \mathrm{~m})$ distance from wind turbine No. 2 corresponding to Figure 7 . It can be seen that there is a clear difference in the vertical distribution of the turbulent intensity at each wind speed. When the wind speed was $11.0 \mathrm{~m} / \mathrm{s}$ or higher, the turbulence intensity gradually decreased as the wind speed increased. Figure $9 \mathrm{~b}$ shows the results for wind speeds of $6.0-10.0 \mathrm{~m} / \mathrm{s}$, which were of particular interest in this study. In this range, the turbulence intensity near the height of the wind turbine hub (78 $\mathrm{m}$ above the ground) is very large compared to other wind speeds. Furthermore, as shown in Figure 8, the vertical distribution is almost the same in the range of the wind turbine swept area $(z=35-121 \mathrm{~m})$, regardless of the wind speed. In this study, it was shown that the amount of wake loss was very large in the wind speed range of 6.0-10.0 m/s, compared to other wind speeds, and that the turbulence intensity was also large in the range of the wind turbine swept area.

Figure 10 shows a comparison of the measured turbulence intensity with the International Electrotechnical Commission (IEC) model. Measurement point is 3D (D = $86 \mathrm{~m})$ distance from wind turbine No.2 and wind turbine hub height $78 \mathrm{~m}$ above the ground. Measurement period is 18 November 2017-20 December 2017. It can be seen that the turbulence intensity is high at wind speeds of 4.0-10.0 m/s and exceeds the most severe turbulence category (Category A). As shown in Figure 3a, the wind turbine starts at a wind speed of $4.0 \mathrm{~m} / \mathrm{s}$ and operates at a rated speed at wind speeds beyond $10.0 \mathrm{~m} / \mathrm{s}$. The turbulence intensity decreases at wind speeds higher than $11.0 \mathrm{~m} / \mathrm{s}$; as mentioned earlier, it is presumed that this is because the pitch angle is controlled so that the wind turbine blade does not become a source of resistance. 

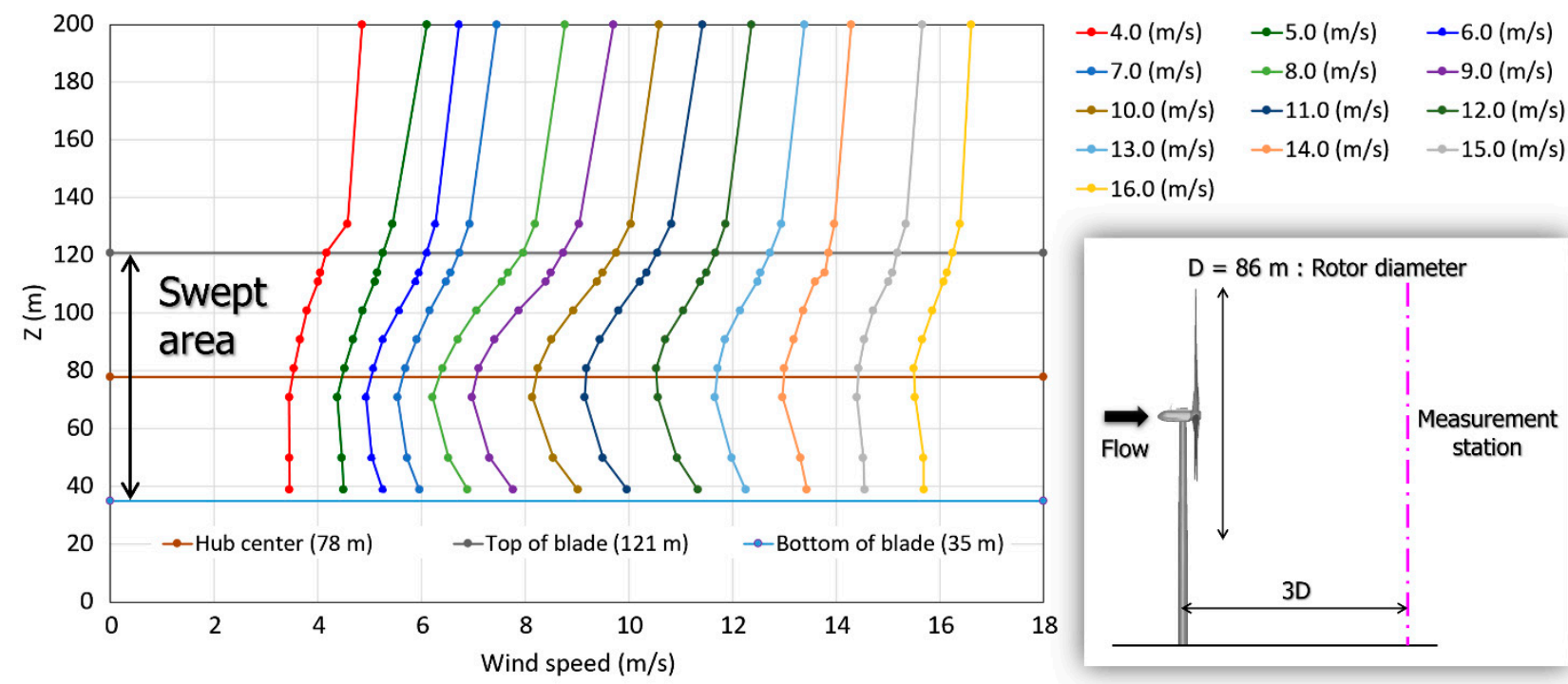

Figure 7. Vertical distribution of lidar-measured mean wind speed in the streamwise direction at each wind speed, 3D distance from wind turbine No.2 $(\mathrm{D}=86 \mathrm{~m})$. Average operations were performed at each altitude. Measurement period: 28 November 2016-2 December 2016 and 17 November 2017-21 December 2017.

Table 1. Number of data points at each wind speed shown in Figure 7, 3D distance from wind turbine No.2 (D = $86 \mathrm{~m})$. Measurement period: 28 November 2016-2 December 2016 and 17 November 2017-21 December 2017.

\begin{tabular}{cccccccccccccc}
\hline $\begin{array}{c}\text { Wind Speed } \\
(\mathbf{m} / \mathbf{s})\end{array}$ & $\mathbf{4}$ & $\mathbf{5}$ & $\mathbf{6}$ & $\mathbf{7}$ & $\mathbf{8}$ & $\mathbf{9}$ & $\mathbf{1 0}$ & $\mathbf{1 1}$ & $\mathbf{1 2}$ & $\mathbf{1 3}$ & $\mathbf{1 4}$ & $\mathbf{1 5}$ & $\mathbf{1 6}$ \\
\hline Number & 5 & 13 & 28 & 36 & 25 & 31 & 43 & 36 & 31 & 31 & 22 & 11 & 6 \\
\hline
\end{tabular}
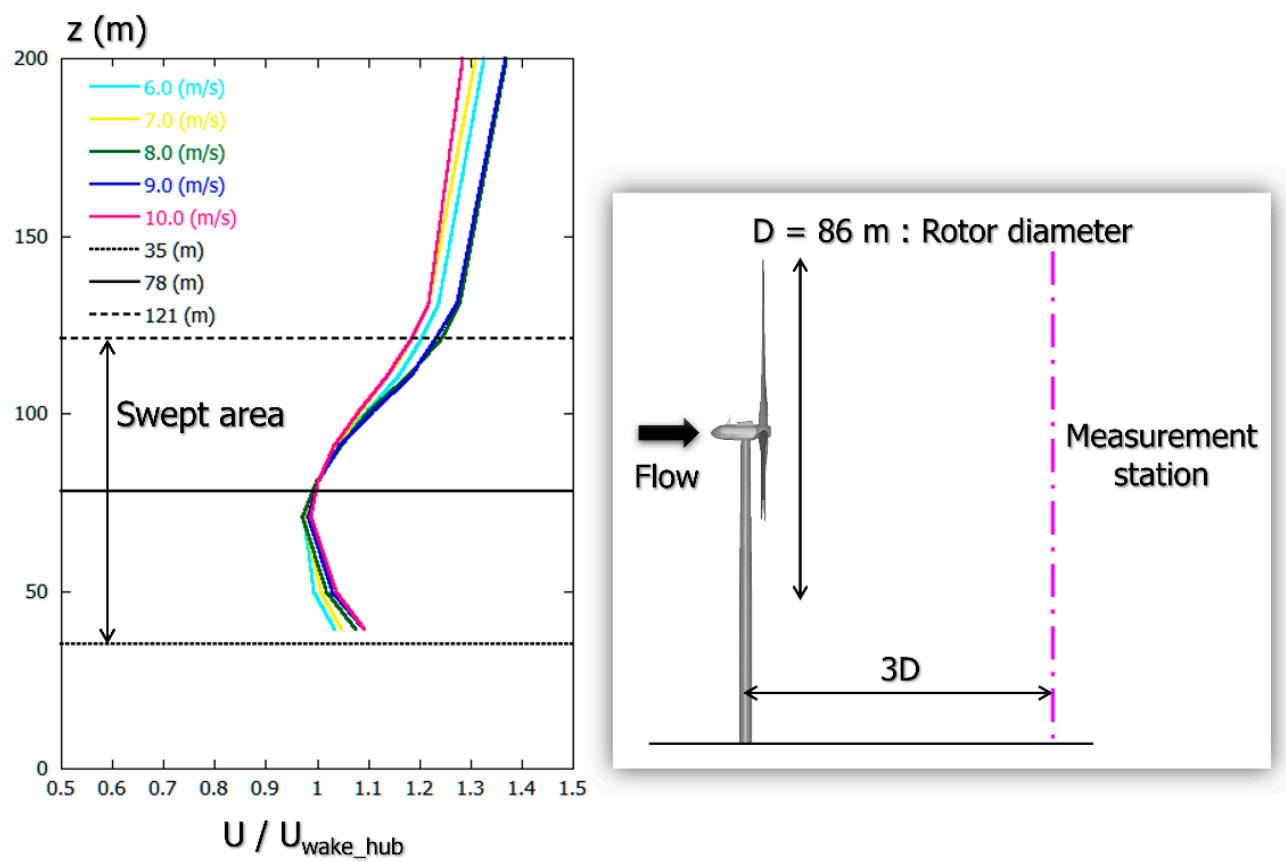

Figure 8. Results for wind speed of 6.0-10.0 m/s shown in Figure 7 normalized by the wind speed near the wind turbine hub height (78 $\mathrm{m}$ above the ground). Measurement period: 28 November 2016-2 December 2016 and 17 November 2017-21 December 2017. 


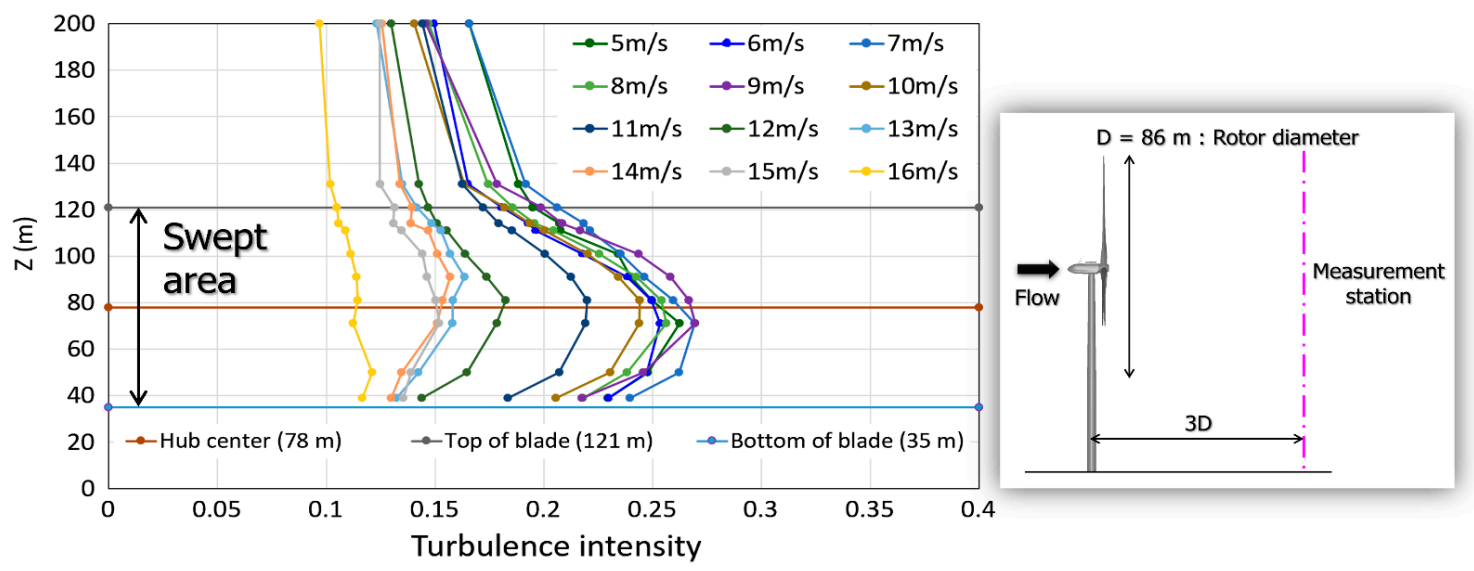

(a)

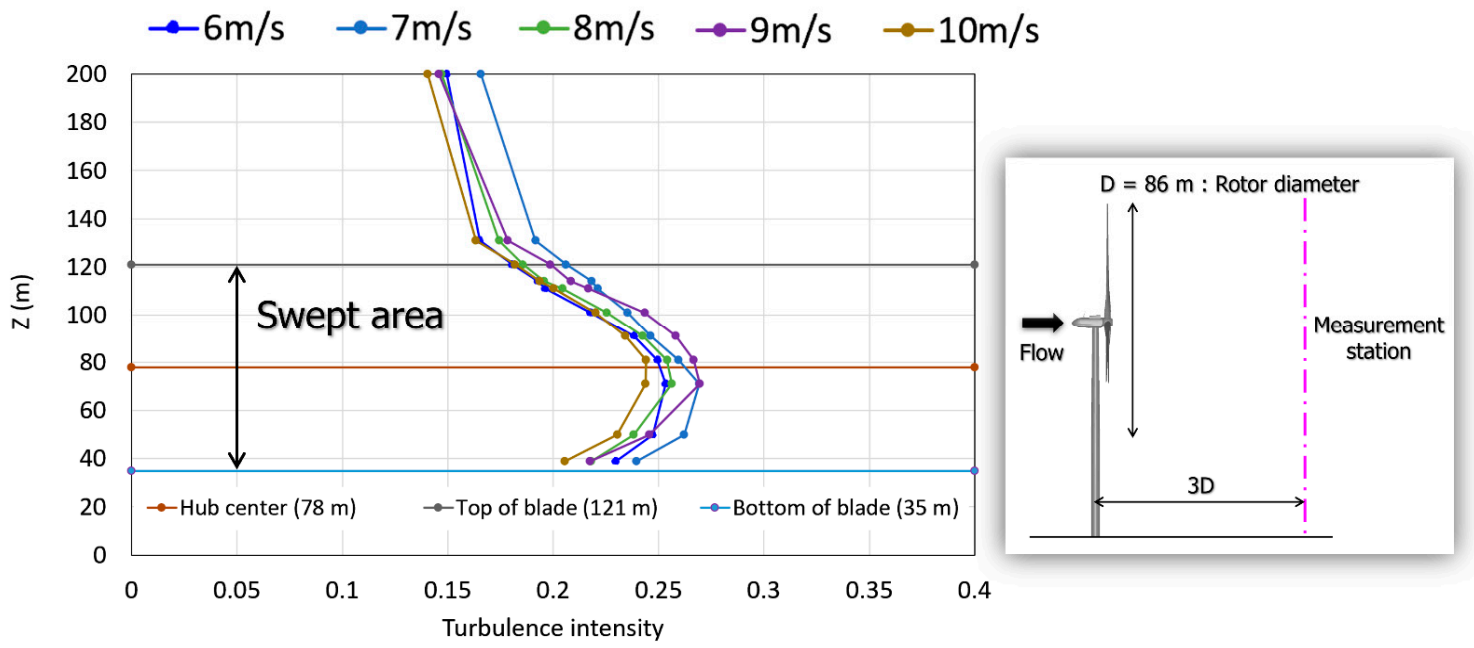

(b)

Figure 9. Vertical distribution of lidar-measured turbulence intensity at 3D distance from wind turbine No.2 (D = $86 \mathrm{~m})$. (a) Wind speed range 5.0-16.0 m/s; (b) wind speed range 6.0-10.0 m/s. Measurement period: 28 November 2016-2 December 2016 and 17 November 2017-21 December 2017.
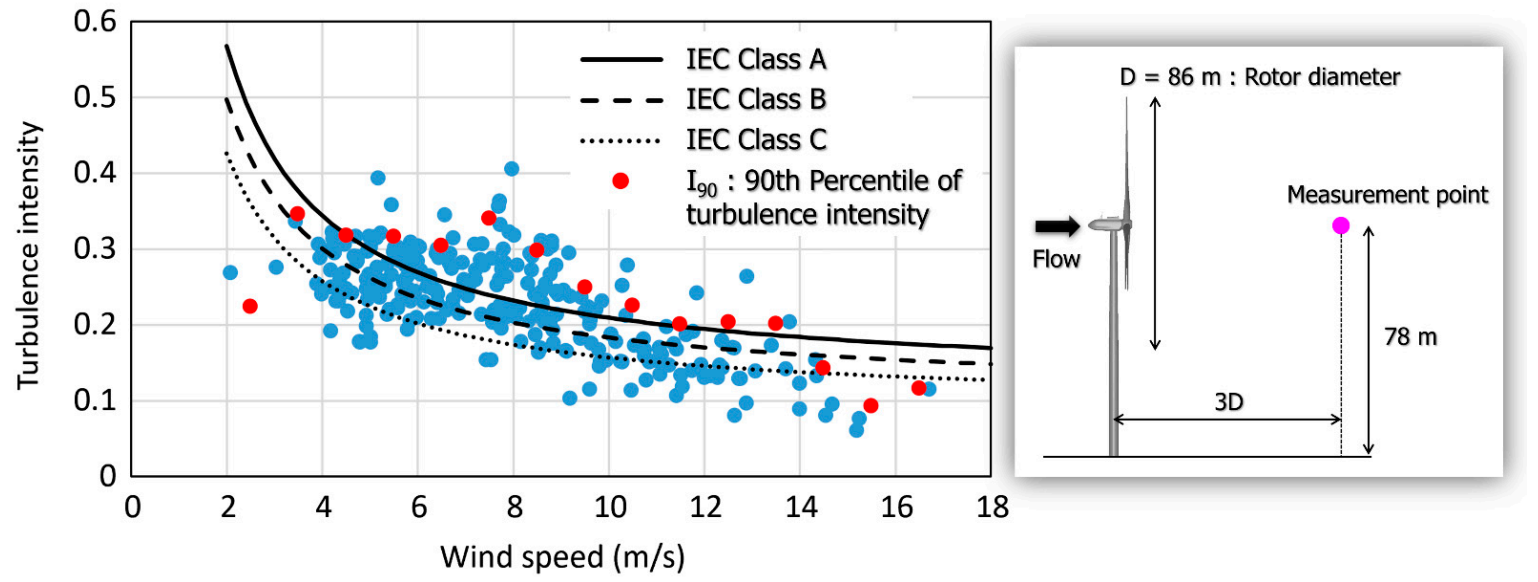

Figure 10. Comparison of lidar-measured turbulence intensity with International Electrotechnical Commission (IEC) normal turbulence model (NTM). Measurement point is 3D distance from wind turbine No.2 (D=86 m) and hub height $78 \mathrm{~m}$ above the ground Measurement period: 18 November 2017-20 December 2017. 
3. Comparison of Wind Measurement Results for Wind Turbine Near-Wake According to Doppler Lidar and Existing Engineering Wake Model

Here, we describe a comparison between the wind measurement results obtained by Doppler lidar and existing engineering wake models such as the Park model $[8,9]$ and Ishihara model [13] derived from the Park model. Details of the Park model [8,9] formulation can be found in Appendix A.

Figure 11 shows the visualization results for the Park model (wind speed in the streamwise direction) at the wind turbine hub height ( $78 \mathrm{~m}$ above the ground) when the wind speed is $8.0 \mathrm{~m} / \mathrm{s}$. It is confirmed that the wake effect extends to the vicinity of the Doppler lidar installed 3D downstream of wind turbine No.2.

Figure 12 shows the wind speed prediction from the Park model (wind speed in the streamwise direction) at the wind turbine hub height ( $78 \mathrm{~m}$ above the ground) when the wind speed is $5.0-15.0 \mathrm{~m} / \mathrm{s}$. Now, please refer to the results of wind speeds of $6.0-10.0 \mathrm{~m} / \mathrm{s}$ in Figure 12, which are our particular focus in this study. The wind speed ratios for the speeds $6.0-10.0 \mathrm{~m} / \mathrm{s}$ are very similar, being the thrust coefficient of the wind turbine (see Figure $3 b$ ) almost constant in this range.

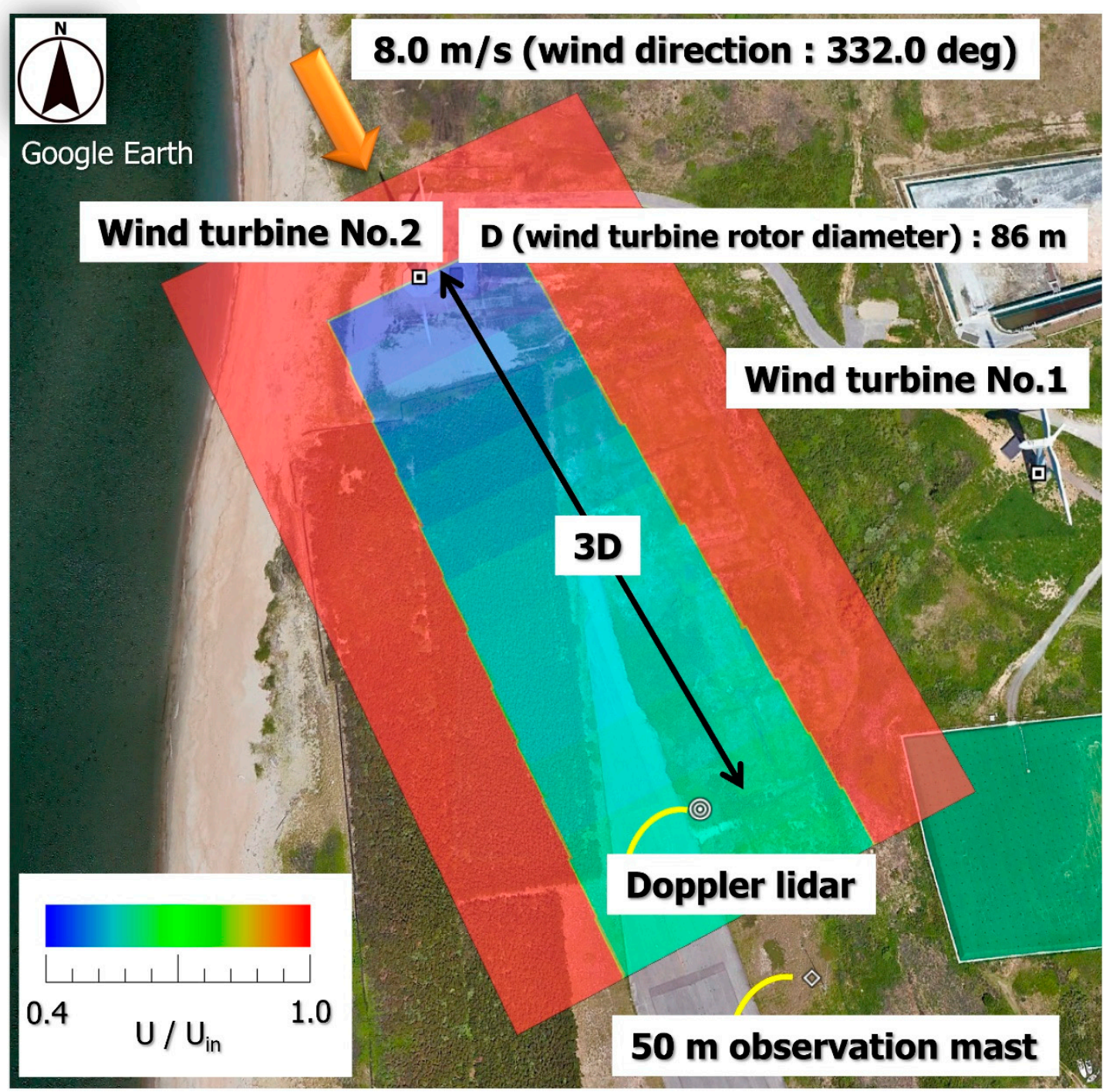

Figure 11. Visualization of wind speed ratio using the Park model (wake decay constant of 0.04) at the wind turbine hub height (78 $\mathrm{m}$ above the ground) under the wind speed of $8.0 \mathrm{~m} / \mathrm{s}$. 


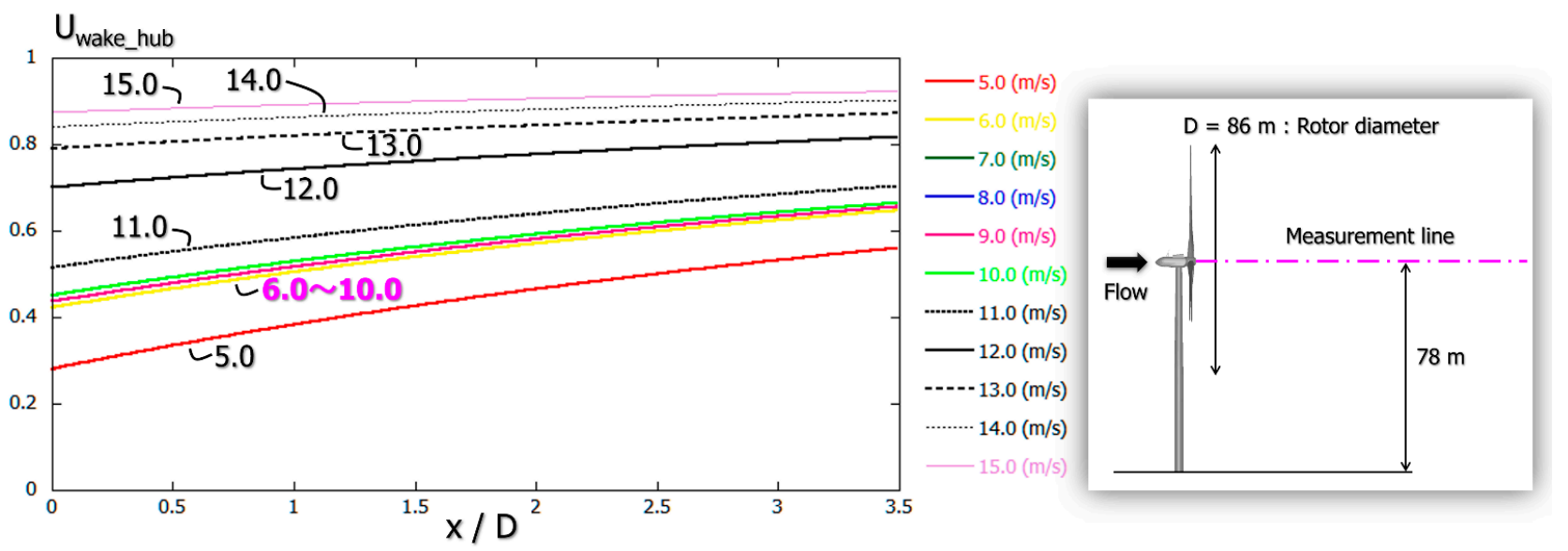

Figure 12. Wind speed ratios using the Park model (wind speed in the streamwise direction) at the wind turbine hub height (78 $\mathrm{m}$ above the ground) under the wind speed of $5.0-15.0 \mathrm{~m} / \mathrm{s}$.

Figure 13 shows a comparison (vertical distribution of the mean wind speed in the streamwise direction) between the prediction results from the Park and Ishihara models, and the measurement results obtained by Doppler lidar 3D $(\mathrm{D}=86 \mathrm{~m})$ downstream of wind turbine No.2 at a wind speed of $8.0 \mathrm{~m} / \mathrm{s}$. The Ishihara model shows results for four typical surface roughness patterns $(\mathrm{N}=3.7,5,6.7$ and 10). A detailed examination of the obtained results revealed that there was a significant difference between the prediction results from the Park and Ishihara models and the measurement results from the Doppler lidar. In other words, it was shown that the prediction results from both the Park and Ishihara models gave a larger amount of wake loss (wind velocity deficit) compared to those from the Doppler lidar.

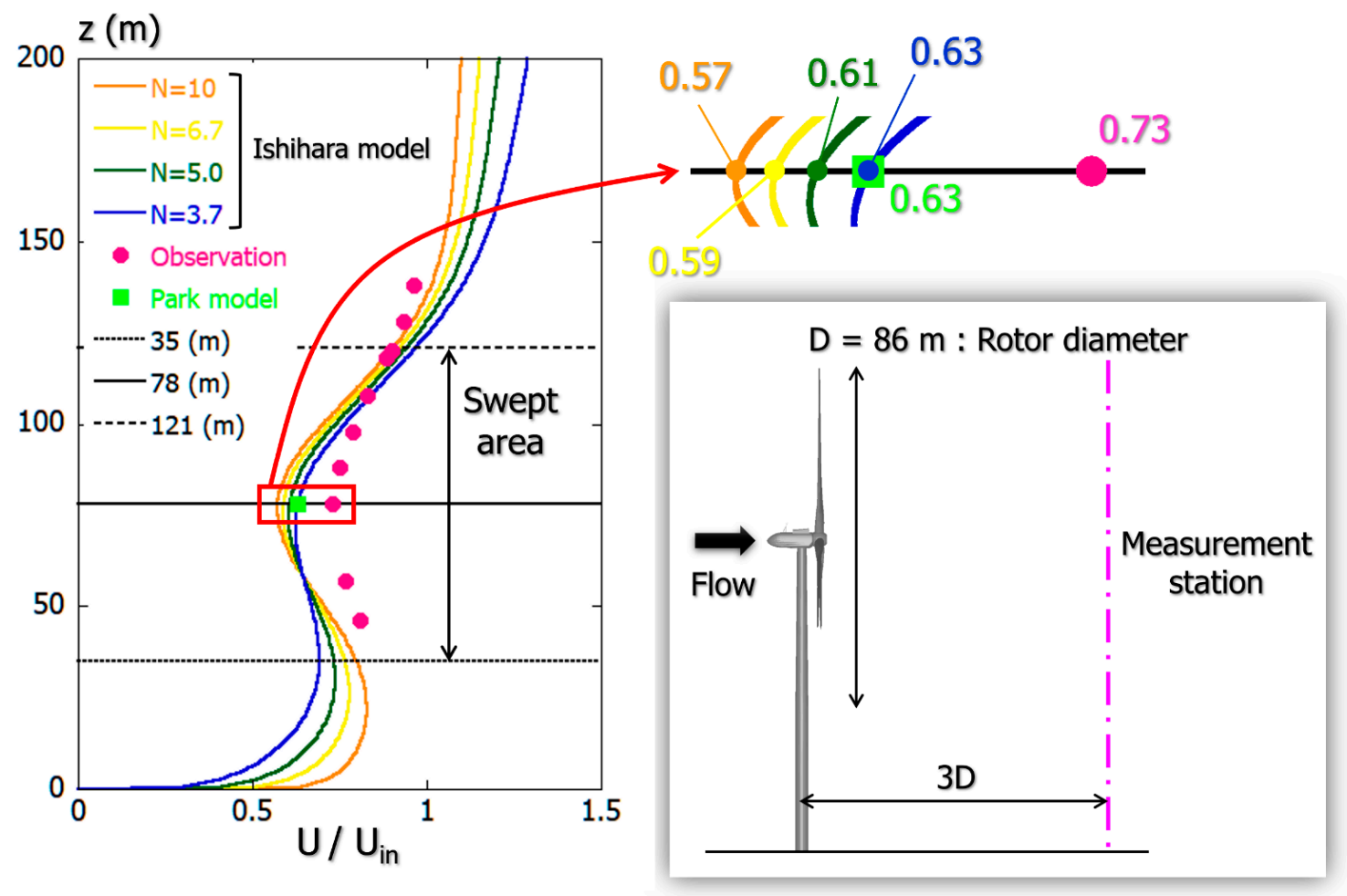

Figure 13. Comparison of Park and Ishihara models with the lidar-measured results at $3 \mathrm{D}(\mathrm{D}=86 \mathrm{~m})$ downstream of wind turbine No.2. Vertical distribution of mean wind speed in the streamwise direction (wind speed $8.0 \mathrm{~m} / \mathrm{s}$ ). 
Figure 14 shows a comparison of the wind velocity deficit. Here, measurement point is $3 \mathrm{D}$ distance from wind turbine No.2 $(\mathrm{D}=86 \mathrm{~m})$ and hub height $78 \mathrm{~m}$ above the ground. The wind speed range is $5.0-15.0 \mathrm{~m} / \mathrm{s}$. Note the measurement results obtained by Doppler lidar shown by the solid red line. As already mentioned, the wind velocity deficit is almost the same at wind speeds of 6.0-10.0 m/s, to which we paid particular attention in this study. Next, we focus on the prediction results from the Park and Ishihara models. In both cases, it was clear that there was a larger amount of wake loss (wind velocity deficit) near the wind turbine hub height (78 $\mathrm{m}$ above the ground), compared with the wind measurement results obtained by the Doppler lidar. Comparing the predicted value from the Park model with that from the Ishihara model, it is apparent that the wind velocity deficit from the Ishihara model becomes large in the wind speed range of $6.0 \mathrm{~m} / \mathrm{s}$ or more.
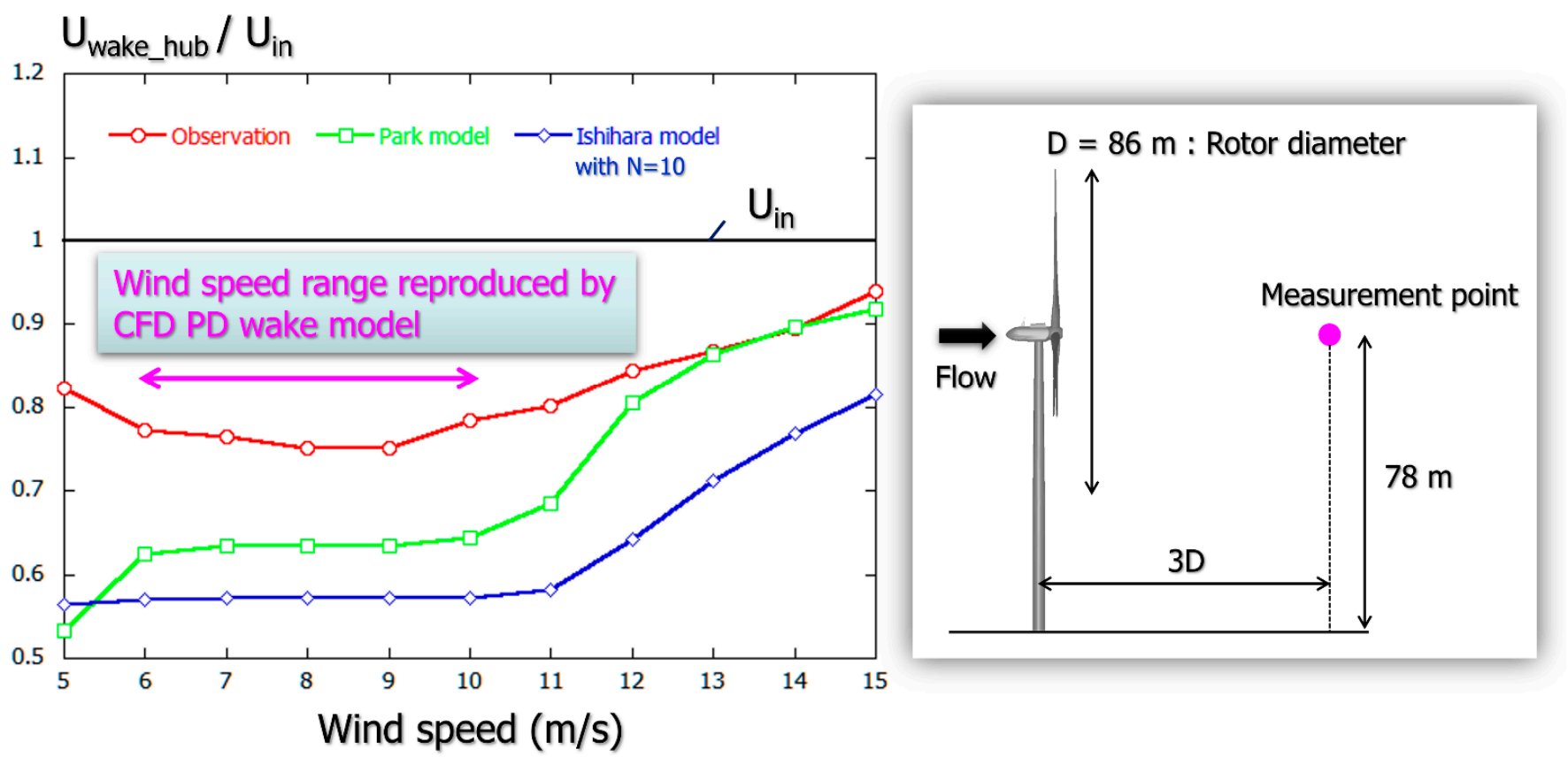

Figure 14. Comparison of wind velocity deficit. Measurement point is 3D distance from wind turbine No.2 (D = $86 \mathrm{~m})$ and hub height $78 \mathrm{~m}$ above the ground. The wind speed range is $5.0-15.0 \mathrm{~m} / \mathrm{s}$.

\section{CFD Simulations Based on Large Eddy Simulation (LES)}

\subsection{Overview of LES-Based CFD Approach}

In the present study, we used the "RIAM-COMPACT" real urban version [14] based on a mixed-time-scale (MTS) subgrid-scale (SGS) model [15] implemented in LES (Equations (1)-(11)). Please refer to the previous papers [16,17] for details of numerical simulation methods.

$$
\begin{gathered}
\frac{\partial \overline{\mathrm{u}}_{\mathrm{i}}}{\partial \mathrm{x}_{\mathrm{i}}}=0 \\
\frac{\partial \overline{\mathrm{u}}_{\mathrm{i}}}{\partial \mathrm{t}}+\overline{\mathrm{u}}_{\mathrm{j}} \frac{\partial \overline{\mathrm{u}}_{\mathrm{i}}}{\partial \mathrm{x}_{\mathrm{j}}}=-\frac{\partial \overline{\mathrm{p}}}{\partial \mathrm{x}_{\mathrm{i}}}+\frac{1}{\operatorname{Re}} \frac{\partial^{2} \overline{\mathrm{u}}_{\mathrm{i}}}{\partial \mathrm{x}_{\mathrm{j}} \partial \mathrm{x}_{\mathrm{j}}}-\frac{\partial \tau_{\mathrm{ij}}}{\partial \mathrm{x}_{\mathrm{j}}} \\
\tau_{\mathrm{ij}} \approx \overline{\mathrm{u}_{\mathrm{i}}^{\prime} \mathrm{u}_{\mathrm{j}}^{\prime}} \approx \frac{1}{3} \overline{\mathrm{u}_{\mathrm{k}}^{\prime} \mathrm{u}_{\mathrm{k}}^{\prime}} \delta_{\mathrm{ij}}-2 v_{\mathrm{SGS}} \bar{S}_{\mathrm{ij}} \\
v_{\mathrm{SGS}}=\mathrm{C}_{\mathrm{MTS}} \mathrm{k}_{\mathrm{es}} \mathrm{T}_{\mathrm{S}} \\
\mathrm{C}_{\mathrm{MTS}}=0.05 \\
\mathrm{k}_{\mathrm{es}}=\left(\overline{\mathrm{u}}_{\mathrm{k}}-\hat{\overline{\mathrm{u}}}_{\mathrm{k}}\right)^{2}
\end{gathered}
$$




$$
\begin{gathered}
\mathrm{T}_{\mathrm{S}}^{-1}=\left(\frac{\Delta}{\sqrt{\mathrm{k}_{\mathrm{es}}}}\right)^{-1}+\left(\frac{\mathrm{C}_{\mathrm{T}}}{\left|\overline{\mathrm{S}}_{\mathrm{ij}}\right|}\right)^{-1} \\
\left|\overline{\mathrm{S}}_{\mathrm{ij}}\right|=\left(2 \overline{\mathrm{S}}_{\mathrm{ij}} \overline{\mathrm{S}}_{\mathrm{ij}}\right)^{1 / 2} \\
\overline{\mathrm{S}}_{\mathrm{ij}}=\frac{1}{2}\left(\frac{\partial \overline{\mathrm{u}}_{\mathrm{i}}}{\partial \mathrm{x}_{\mathrm{j}}}+\frac{\partial \overline{\mathrm{u}}_{\mathrm{j}}}{\partial \mathrm{x}_{\mathrm{i}}}\right) \\
\mathrm{C}_{\mathrm{T}}=10.0 \\
\Delta=\left(\Delta_{\mathrm{x}} \cdot \Delta_{\mathrm{y}} \cdot \Delta_{\mathrm{z}}\right)^{1 / 3}
\end{gathered}
$$

\subsection{Inflow Turbulence Generation Methods and Consideration}

Inflow turbulence was artificially generated and imposed as an inflow airflow condition in order to verify the effectiveness of the CFD PD wake model [10] in a real field environment. Here, we explain the methods for artificially generating the inflow turbulence.

Figure 15 shows a conceptual diagram of the inflow turbulence generation methods. The recycling method by Lund [18] was simplified and used. The grid resolution in all directions was $2 \mathrm{~m}(\Delta \mathrm{x}=\Delta \mathrm{y}=\Delta \mathrm{z}=2 \mathrm{~m})$. Therefore, the total number of grids was approximately 41 million points. Concerning the boundary conditions, a power law distribution following $\mathrm{N}=10$ was assigned to inflow conditions (Equation (12)). Other boundary conditions are the same as in previous paper [14]. The time step was set to $\Delta \mathrm{t}=\left(1 \times 10^{-3}\right) \mathrm{R} / \mathrm{U}_{\mathrm{in}}$, where the Courant number was less than about 1.0. In addition, the variable $R$ represents the rotor radius.

$$
\mathrm{U}=\mathrm{U}_{\mathrm{in}} \times\left\{\frac{\mathrm{z}(\mathrm{m})}{78}\right\}^{\frac{1}{\mathrm{~N}}}, \text { where } \mathrm{U}_{\mathrm{in}}=\mathrm{U}(78)
$$

Turbulent fluctuations (fluctuating velocity: $\mathrm{u}^{\prime}(\mathrm{t}, \mathrm{x}, \mathrm{y}, \mathrm{z}), \mathrm{v}^{\prime}(\mathrm{t}, \mathrm{x}, \mathrm{y}, \mathrm{z})$ and $\mathrm{w}^{\prime}(\mathrm{t}, \mathrm{x}, \mathrm{y}$, $z)$ ) on a sampling plane were recycled back to the inlet as the inflow boundary condition. After that, time integration was performed until the flow field was fully developed, and turbulent flow data (instantaneous velocity: $\mathrm{u}(\mathrm{t}, \mathrm{x}, \mathrm{y}, \mathrm{z}), \mathrm{v}(\mathrm{t}, \mathrm{x}, \mathrm{y}, \mathrm{z})$ and $\mathrm{w}(\mathrm{t}, \mathrm{x}, \mathrm{y}, \mathrm{z})$ ) in the sampling plane at a position different from the above were temporarily saved to disk space. These datasets were used as inflow conditions for the main domain that simulated the wind turbine wake. A single two-dimensional (2D) roughness element was placed on the ground in order to obtain turbulent flows in a short period of time. In other words, it could trigger the laminar-turbulent boundary-layer transition.

Figure 16 shows the spatial distribution of the instantaneous dimensionless U-velocity in the central cross section of the span, from immediately after the start of the CFD simulation to the time when the flow field was fully developed. From the dimensionless time $\mathrm{t}^{*}\left(=\mathrm{t} \mathrm{U}_{\mathrm{in}} / \mathrm{R}, \mathrm{R}\right.$ represents the rotor radius $)=0.5$ shown in Figure $16 \mathrm{a}$ to the dimensionless time 100.0 shown in Figure 16e, the single 2D roughness element described above was installed on the ground. From the dimensionless time 200.0 shown in Figure $16 \mathrm{f}$ to the dimensionless time 300.0 shown in Figure 16g, the single 2D roughness element was removed. By observing these figures, it is clear that a separation flow is formed from the single 2D roughness element, moves to the downstream side, and flows again from the inflow boundary cross section. It is observed that the laminar-turbulent boundary-layer transition occurs with the passage of time and that inflow turbulence is generated over the entire computational domain. 
Turbulent fluctuations (fluctuating velocity : $u^{\prime}(t, x, y, z), v^{\prime}(t, x, y, z), w^{\prime}(t, x, y, z)$ ) on a sampling plane are recycled back to the inlet as inflow boundary condition.

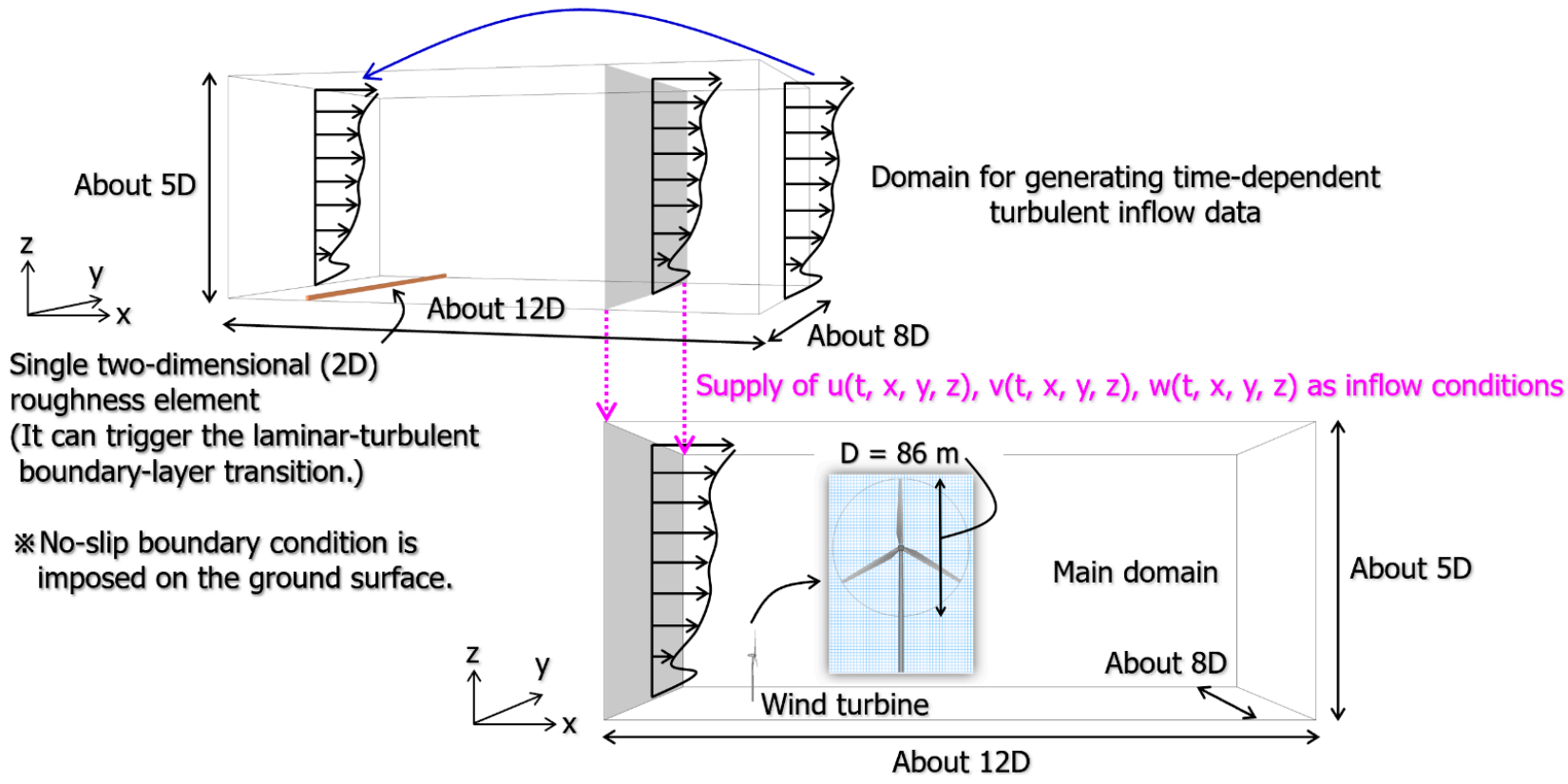

Figure 15. Conceptual diagram of wind turbine wake simulation considering inflow turbulence.

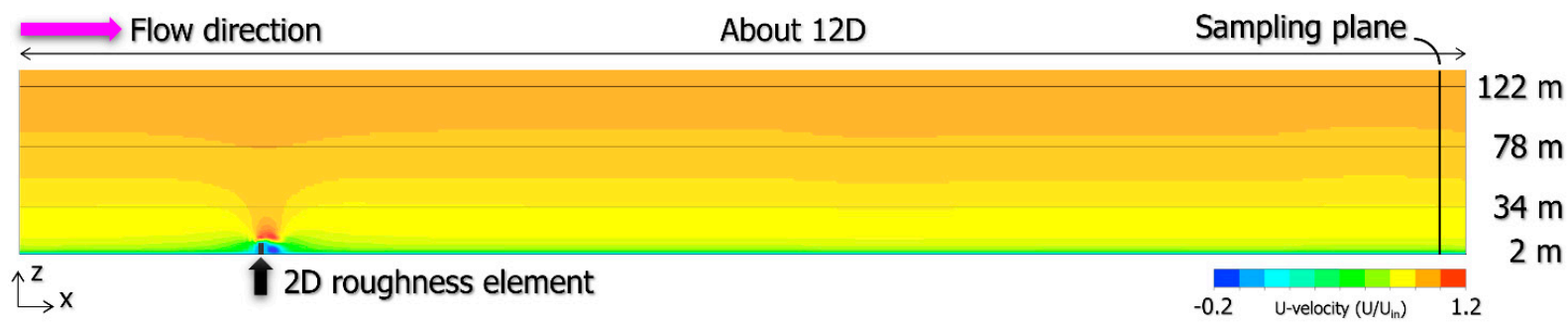

(a)

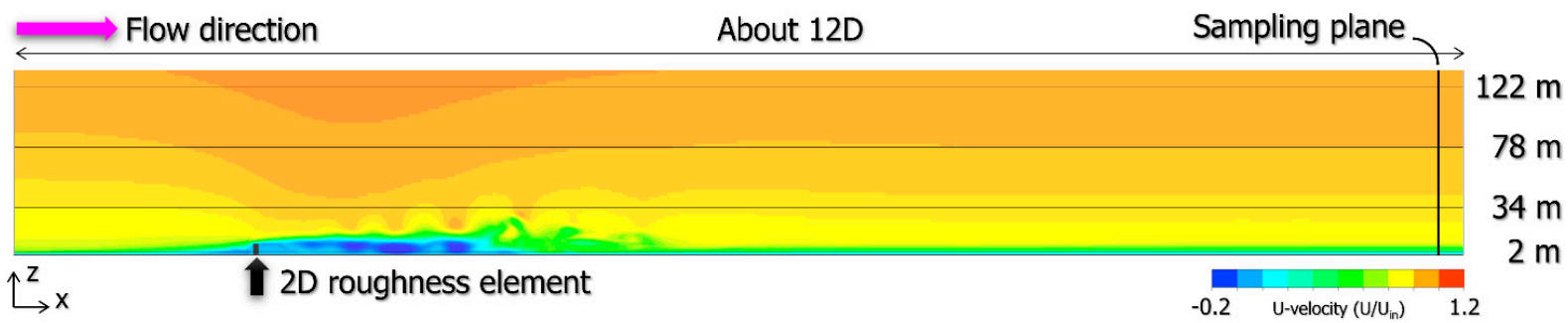

(b)

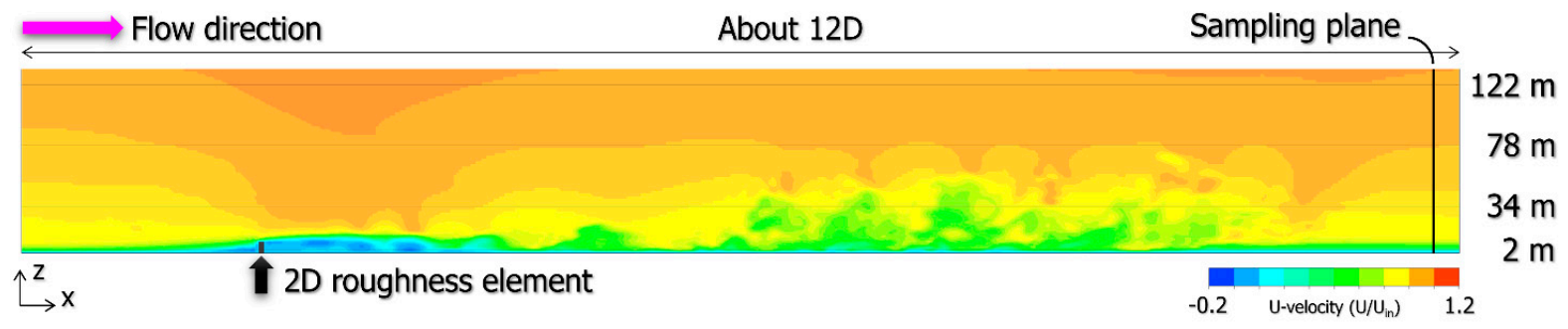

(c)

Figure 16. Cont. 


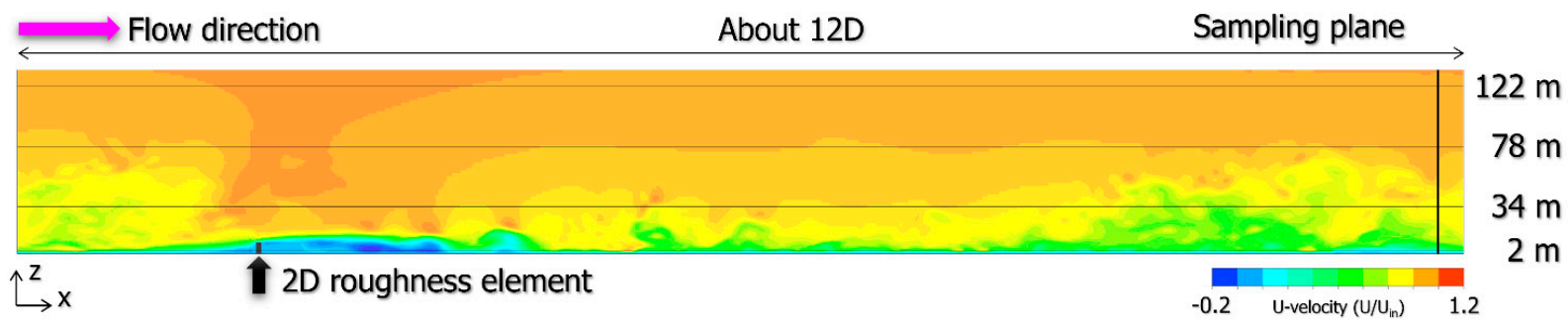

(d)

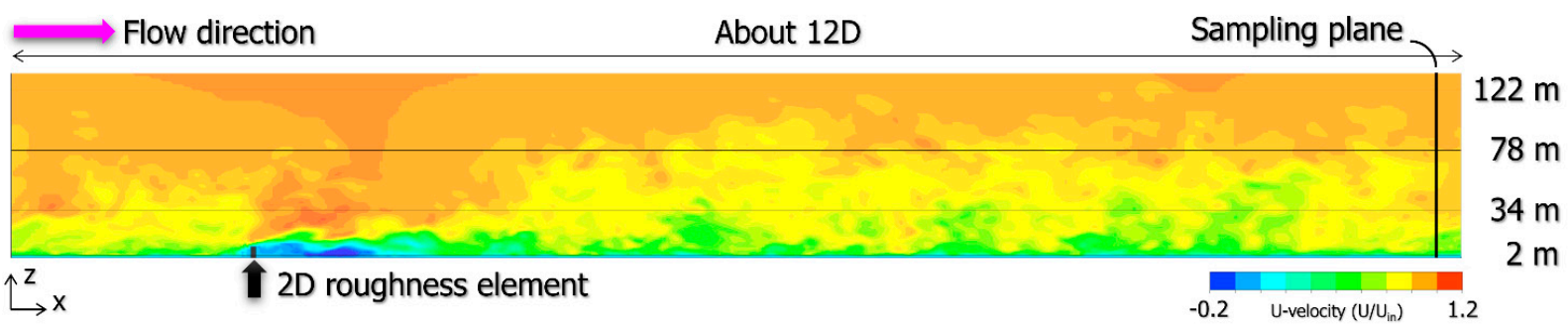

(e)

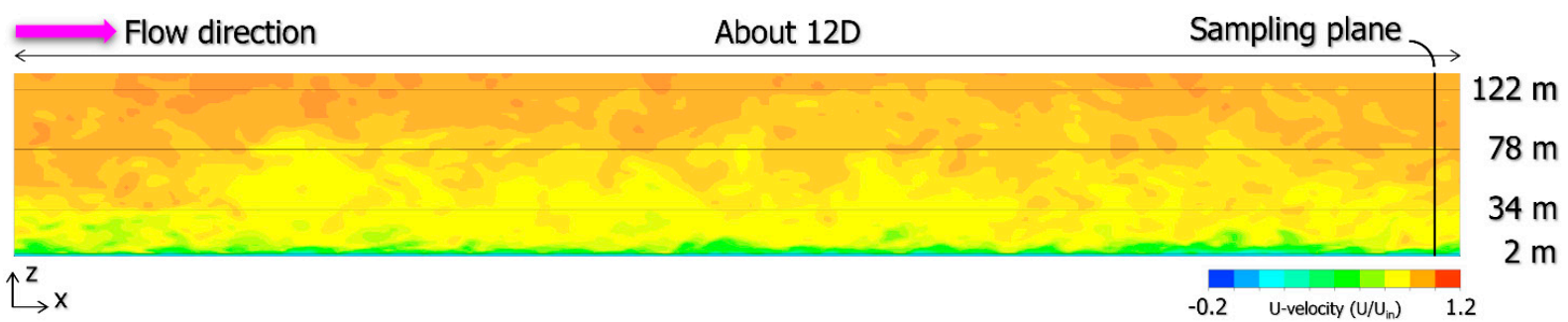

(f)

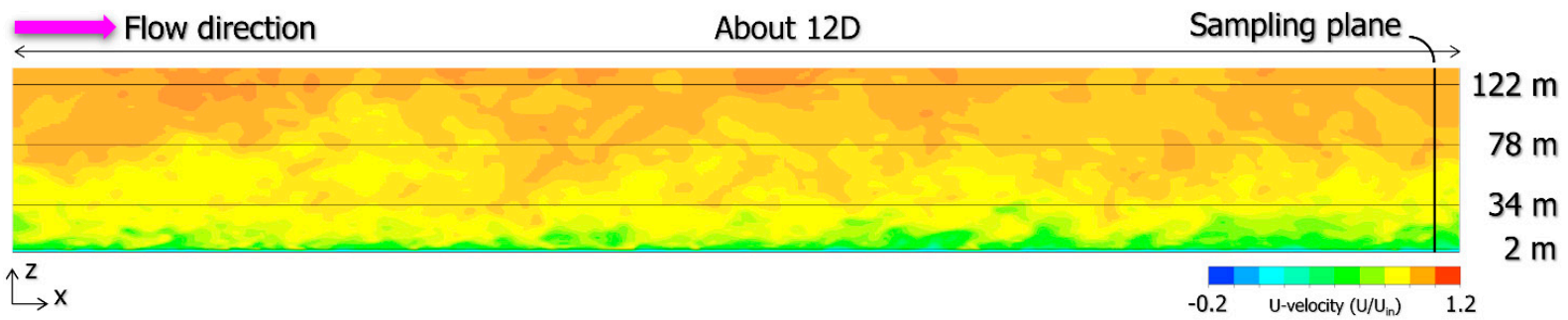

$(\mathrm{g})$

Figure 16. Side view of spatial distribution of instantaneous U-velocity. Here, D (=86 m) shows the rotor diameter. (a) Dimensionless time $\mathrm{t}^{*}=0.5 ;(\mathbf{b}) \mathrm{t}^{*}=34.5 ;(\mathbf{c}) \mathrm{t}^{*}=48.0 ;(\mathbf{d}) \mathrm{t}^{*}=55.5 ;(\mathbf{e}) \mathrm{t}^{*}=100.0 ;(\mathbf{f}) \mathrm{t}^{*}=200.0 ;$ and $(\mathrm{g}) \mathrm{t}^{*}=300.0$.

Figure 17 shows a rear view of the spatial distribution of the instantaneous U-velocity at the sampling plane. Here, the dimensionless time is $t^{*}=200.0$. The position of the swept area of the wind turbine is also described in the figure. It can be seen that the flow field is sufficiently developed in both the $y$ and $z$ directions. Focusing especially on the $z$ direction, it can be seen that the height of the turbulent boundary layer generated in this study is sufficiently higher than the blade top of the wind turbine; that is, the wind turbine is completely buried in the turbulent boundary layer.

Figure 18 shows a top view of the spatial distribution of the instantaneous U-velocity at $\mathrm{z}=2,34,78$ and $122 \mathrm{~m}$ at the time corresponding to Figure 17 . At $\mathrm{z}=2 \mathrm{~m}$ near the ground, it can be seen that very fine vortex structures are formed. A relatively large vortex structures occur, as the altitude from the ground gradually increases. 


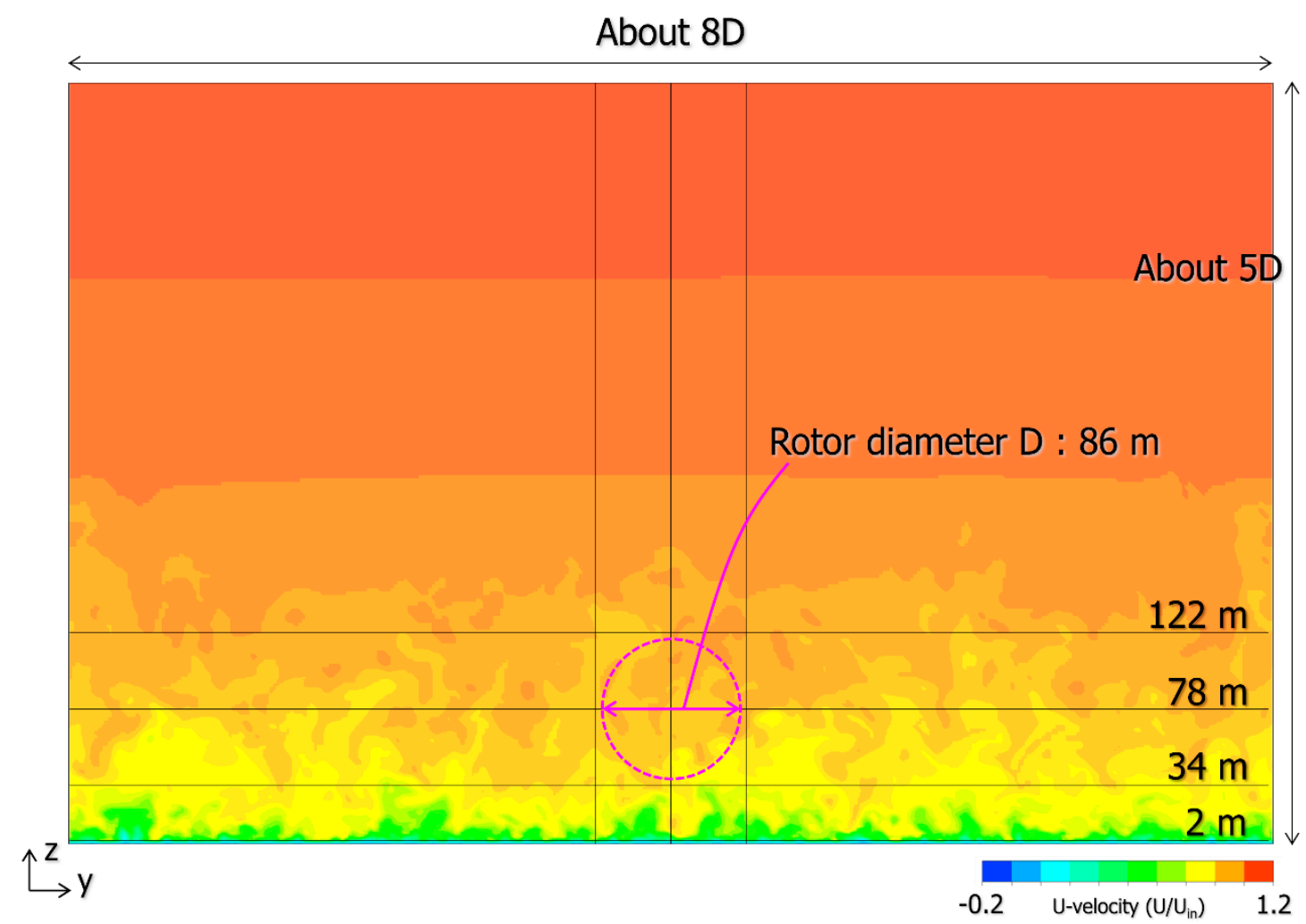

Figure 17. Rear view of spatial distribution of instantaneous U-velocity at sampling plane, dimensionless time $t^{*}=200.0$.

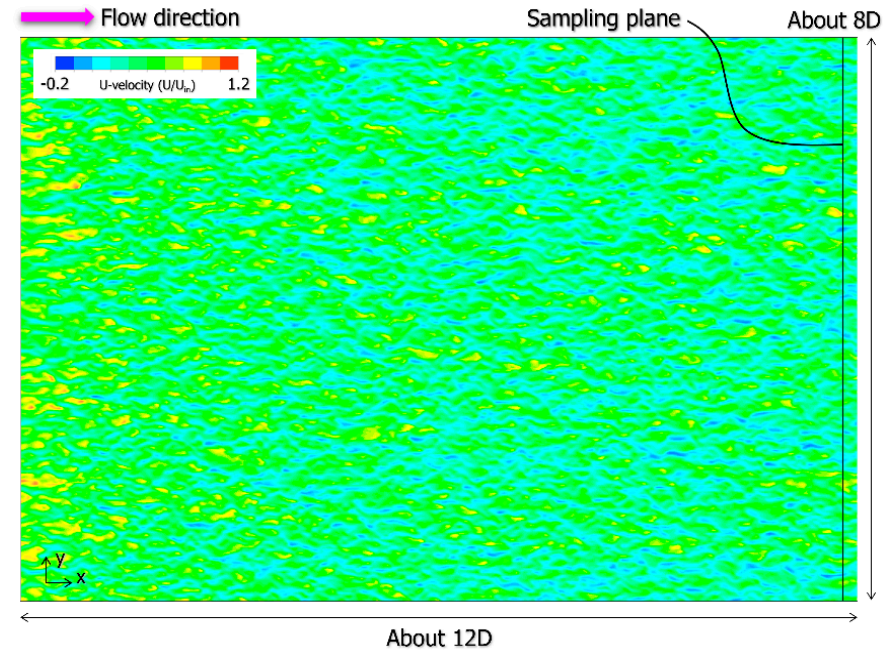

(a)

Figure 18. Cont. 


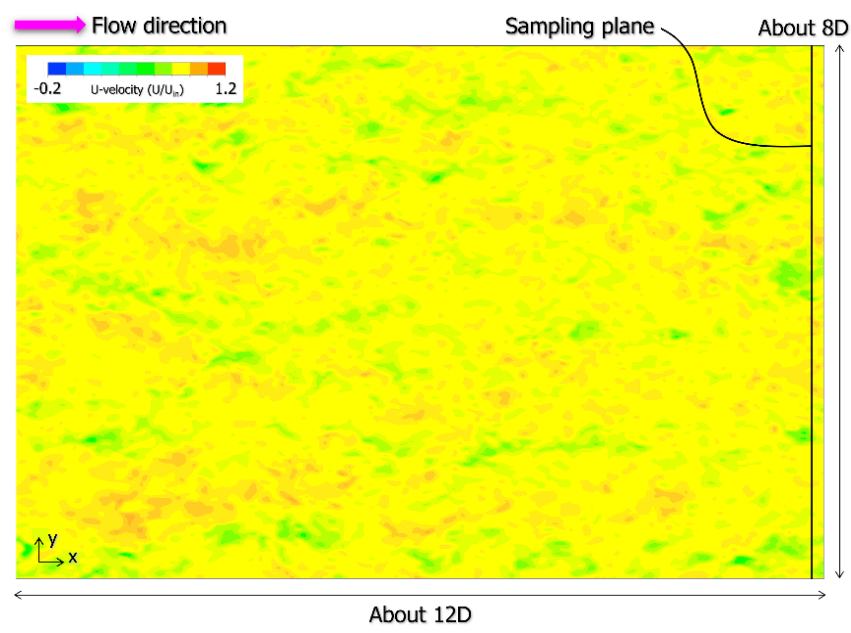

(b)

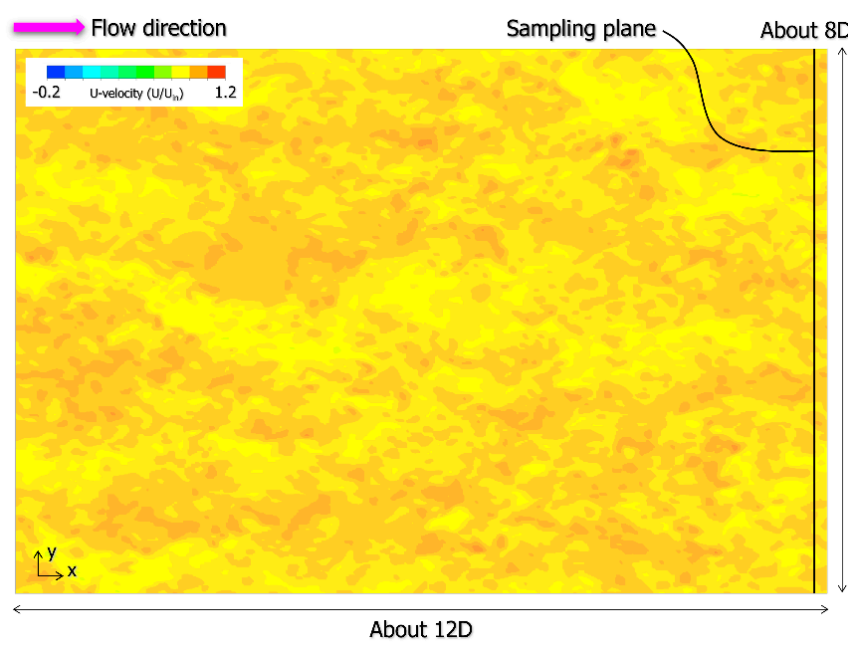

(c)

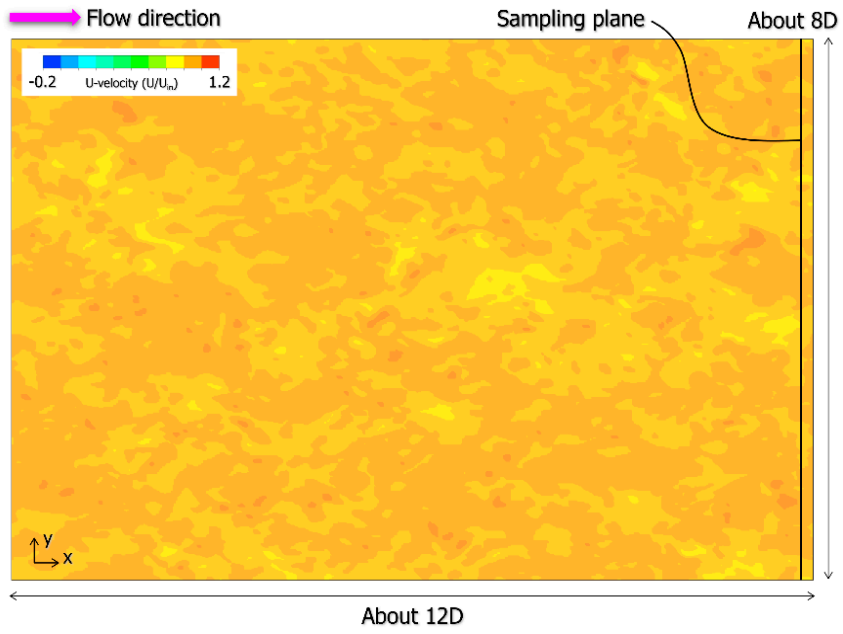

(d)

Figure 18. Top view of spatial distribution of instantaneous U-velocity at dimensionless time $\mathrm{t}^{*}=200.0$. Here, $\mathrm{D}(=86 \mathrm{~m})$ shows the rotor diameter. (a) $\mathrm{z}=2 \mathrm{~m} ;(\mathbf{b}) \mathrm{z}=34 \mathrm{~m} ;(\mathbf{c}) \mathrm{z}=78 \mathrm{~m}$; and $(\mathbf{d}) \mathrm{z}=122 \mathrm{~m}$. 
Figure 19 shows the mean velocity profile and corresponding three standard deviations evaluated by the sampling plane. Focusing on the mean velocity profile shown in Figure 19a, it can be seen that the numerical results represented by the solid black line reproduce the target profile well (power law distribution with $\mathrm{N}=10$ ) shown by the purple circle symbol. On the other hand, in the vertical distribution of the three standard deviations shown in Figure 19b, the velocity fluctuations are in the order of $\sigma_{\mathrm{u}}>\sigma_{\mathrm{v}}>\sigma_{\mathrm{w}}$ in the wind turbine swept area. The figure shows the ratio to the standard deviation in the streamwise direction. Here, the position in which they were evaluated is the height of the wind turbine hub $(\mathrm{z}=78 \mathrm{~m})$.

As described above, it was shown that a well-developed turbulent boundary layer can be formed temporally and spatially by using a simplification of the Lund recycling method. In the next section, we explain the wind turbine wake simulation when the turbulent flow data (instantaneous velocity: $\mathrm{u}(\mathrm{t}, \mathrm{x}, \mathrm{y}, \mathrm{z}), \mathrm{v}(\mathrm{t}, \mathrm{x}, \mathrm{y}, \mathrm{z})$ and $\mathrm{w}(\mathrm{t}, \mathrm{x}, \mathrm{y}, \mathrm{z}))$ generated here are imposed as inflow conditions.

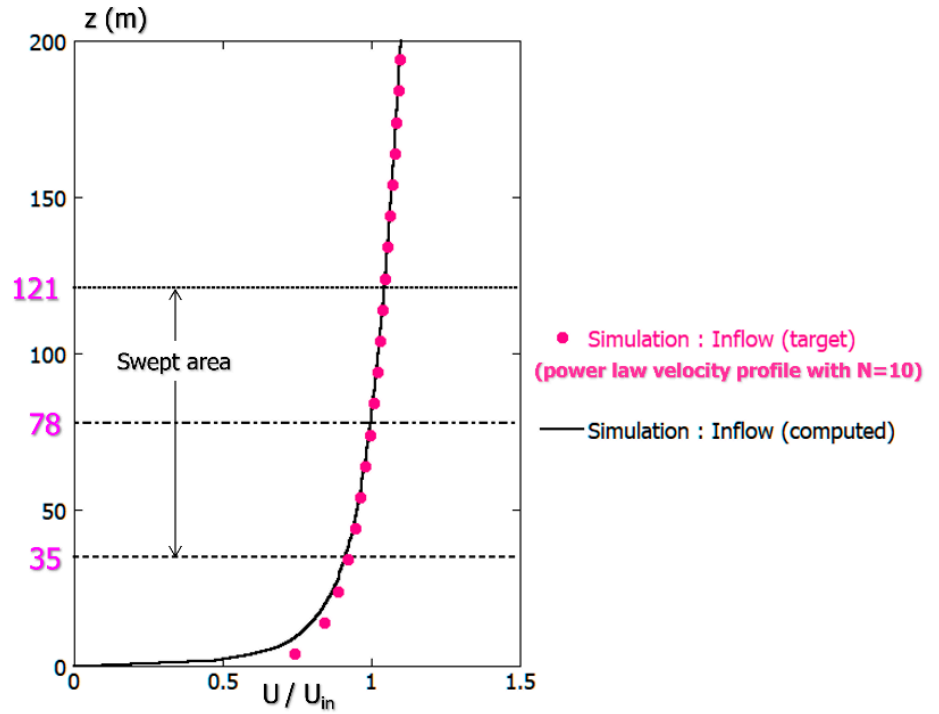

(a)

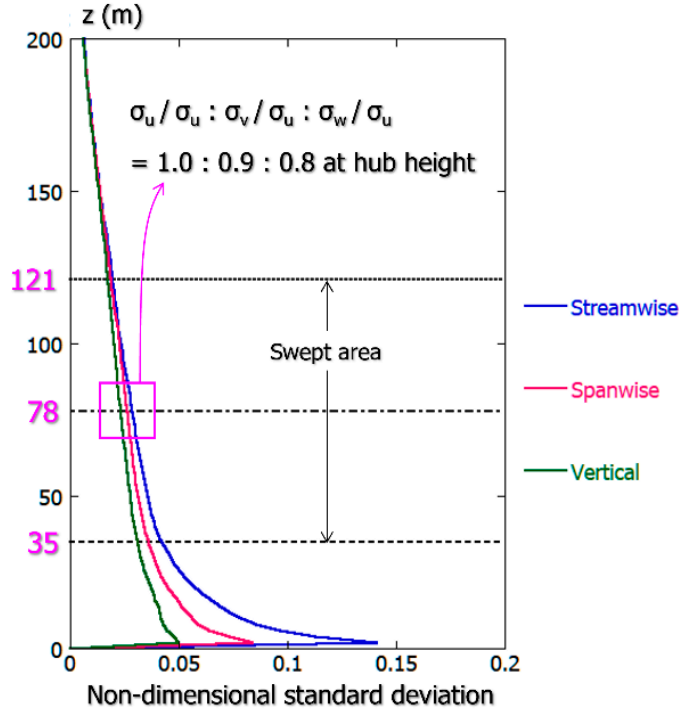

(b)

Figure 19. Vertical distribution characteristics of turbulence statistics evaluated by the sampling plane. (a) Mean velocity profile; (b) corresponding three standard deviations.

\subsection{Large Eddy Simulation (LES) of the Wind Turbine Near-Wake Flow Field Using CFD PD} Wake Model and Consideration

The numerical simulation method is almost the same as that in the previous section, but in order to reproduce the behavior of the $2 \mathrm{MW}$-class downwind turbine wake, we used the CFD PD wake model that we recently developed [10]. The effect of the CFD PD wake model, described in Equations (13) and (14), was implemented as an external force in Equation (2).

$$
\begin{gathered}
F_{i}=C_{R C} \cdot f(y / R, z / R) \cdot \bar{u}_{i} \cdot V \\
V=\sqrt{\bar{u}^{2}+\bar{v}^{2}+\bar{w}^{2}}
\end{gathered}
$$

The only parameter of the CFD PD wake model, $\mathrm{C}_{\mathrm{RC}}$, is the resistance coefficient. The purpose of the simulation in this study was to reproduce the Doppler lidar-based wind field measurement in the wind turbine near-wake region $(x / D=3$, rotor diameter $\mathrm{D}=86 \mathrm{~m}$ ). For this purpose, we conducted a thorough preliminary investigation of the resistance coefficient ( $C_{R C}=1.0$ to 10 in 0.5 increments), based on which we adopted 2.5 for the coefficient $\left(\mathrm{C}_{\mathrm{RC}}\right)$, with a cosine-shaped distribution function in the swept area, as we have already shown in our previous paper [10]. 
Figure 20 shows the computational domain, computational grid, coordinate system, etc. employed in this study. Of particular note is the fact that the spatial grid resolution in each direction was set at equal intervals of $2 \mathrm{~m}$. As a result, the total number of grid points was about 41 million. In this study, parallel simulations were performed using the supercomputer "SX-Aurora TSUBASA", owned by the RIAM, Kyushu University.

In this study, four patterns of simulations were performed as shown in Table 2. As already explained, the CFD PD wake model was applied to the swept area in all cases. Case 1 considered the effects of nacelle, tower and inflow turbulence. Case 2 considered the effects of nacelle and inflow turbulence. In Case 3, only the effect of inflow turbulence was considered. Case 4 did not consider the effects of nacelle, tower and inflow turbulence. By comparing the results of these simulations, the effect on the airflow characteristics in the wind turbine near-wake region $(x / D=3)$ was examined in detail.

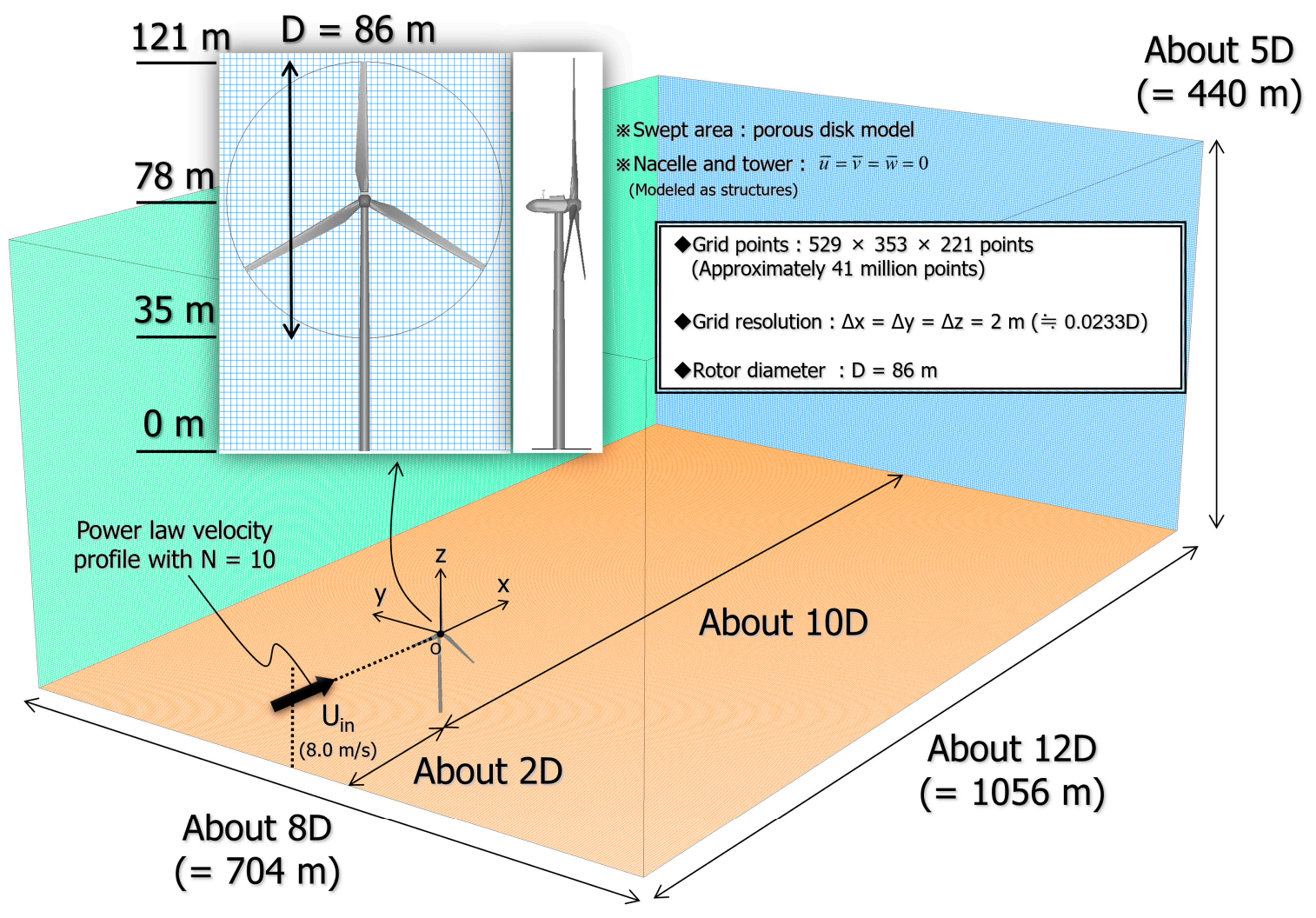

Figure 20. Computational domain, computational grid, coordinate system, etc.

Table 2. Simulation cases. Symbol $\bigcirc$ means that the item on the left was considered, and symbol $\times$ means that the item on the left was not considered.

\begin{tabular}{ccccc}
\hline & Case 1 & Case 2 & Case 3 & Case 4 \\
\hline $\begin{array}{c}\text { Blade (swept area): } \\
\text { CFD PD wake model } \\
\left(\mathrm{C}_{\mathrm{RC}}=2.5\right)\end{array}$ & & & & \\
\hline Nacelle: body $\%$ & & & & \\
\hline Tower: body $*$ & 0 & 0 & $\times$ & $\times$ \\
\hline Inflow turbulence & & 0 & $\times$ & $\times$ \\
\hline
\end{tabular}


Figure 21 shows a side view of the spatial distribution of the instantaneous U-velocity in Cases 1 to 4 . Note first the simulation result shown in Figure 21a, which considers all the inflow turbulence, and the separation flow from the nacelle and tower. In the vicinity of the wind turbine $(x / D<1)$, the reduction (dimensionless $U$-velocity $<1.0$ ) of the wind speed by the CFD PD wake model applied to the swept area and the separation flows from the wind turbine nacelle and tower are clearly observed. These flow fields interfere with each other, resulting in the formation of complex wake flows on the downstream side of the wind turbine $(1 \leq x / D)$. On the other hand, we can see that the inflow turbulence set in the inflow cross section approaches the wind turbine with almost no dissipation of its fluctuations. We can also see that inflow turbulence directly affects the flow field formed near the wind turbine. Additionally, wind speed fluctuations are clearly present even in the far wake region at $x=10 \mathrm{D}$. Next, note the numerical results of Cases 2 and 3 shown in Figure $21 b, c$, respectively. In the vicinity of the wind turbine $(x / D<1)$, there is a slight difference in the flow field formed behind the wind turbine due to the difference in the reproduction of the separated flow from the nacelle and tower. However, the overall behavior of the wake flows at $1 \leq \mathrm{x} / \mathrm{D}$ is not significantly different from the numerical results in Figure 21a. The spatial variation of the wake flows seen in Figure 21a-c cannot be confirmed in Case 4, shown in Figure 21d, in which only the CFD PD wake model is applied to the wind turbine swept area without considering the inflow turbulence, and the separation flows from the nacelle and the tower. However, the overall behavior of wake flows including the wake width in $1 \leq \mathrm{x} / \mathrm{D}$ is similar to that of Figure 21a-c.

Figure 22 shows the rear view at $x=3 \mathrm{D}$ (near-wake region) corresponding to Figure 21. Even though there are differences in the flow patterns around the wind turbine with and without the consideration of inflow turbulence etc., no significant difference can be confirmed in the wind speed distribution (dimensionless U-velocity $<1.0$ ) within the swept area in all the cases.

Figure 23 shows a side view of the spatial distribution of the time-averaged U-velocity in Cases 1 to 4 . Figure 24 shows a rear view at $x=3 D$ (near-wake region) corresponding to Figure 23. In this study, the dimensionless time was defined using the radius of the wind turbine blade and the wind speed at the wind turbine hub height. We have taken averages over a sufficiently long time of 100 (dimensionless time). Even though there are differences in the simulation conditions in each case, we found that the qualitative behavior of the wake flows formed behind the wind turbine is extremely similar. In the rear view at $x=3 \mathrm{D}$ shown in Figure 24, almost concentric wake regions can be seen to have formed behind the wind turbine in all cases.

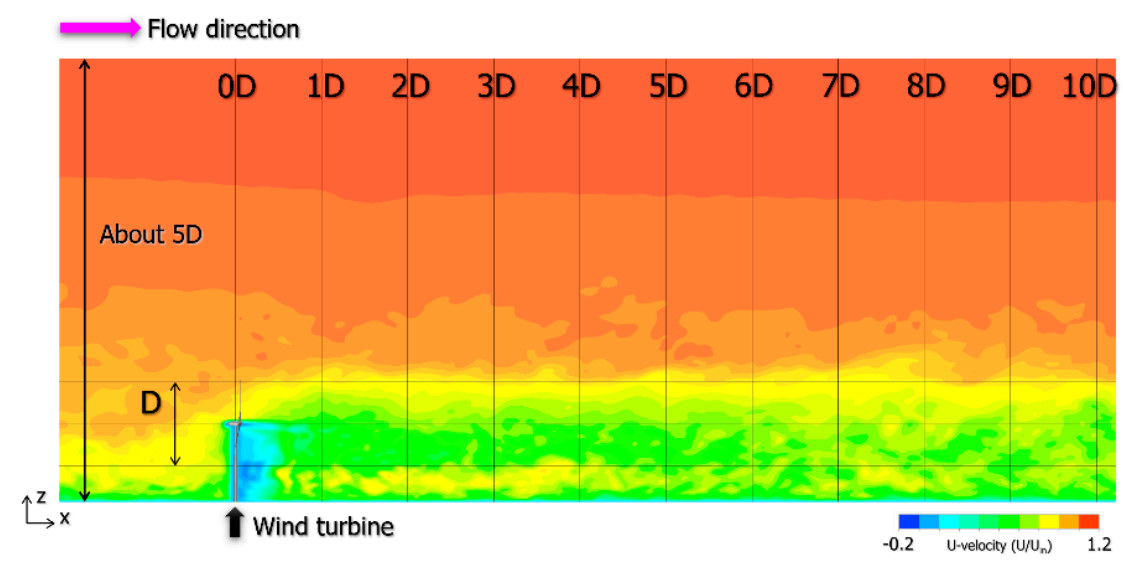

(a)

Figure 21. Cont. 


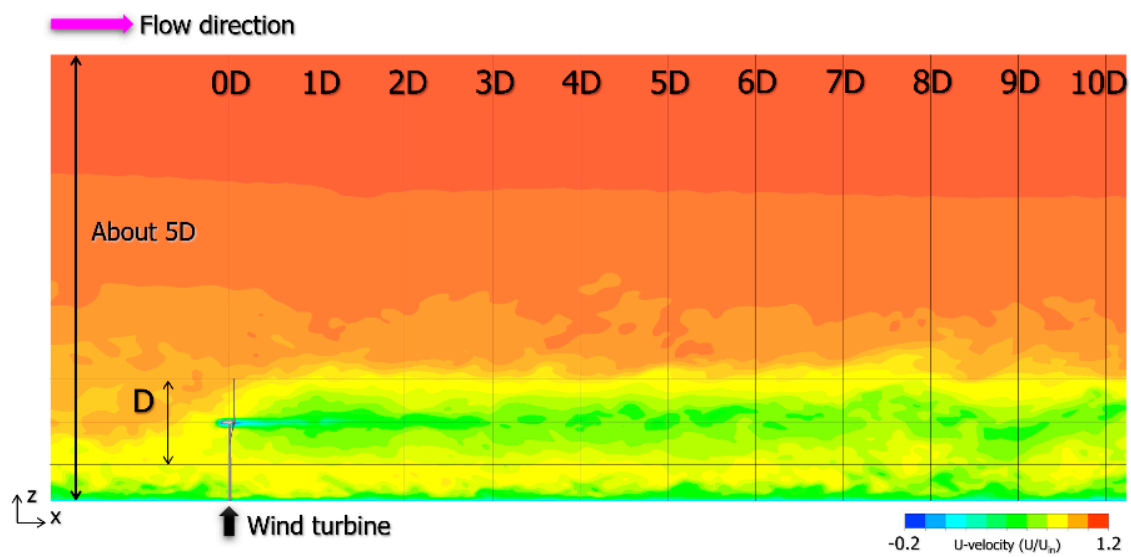

(b)

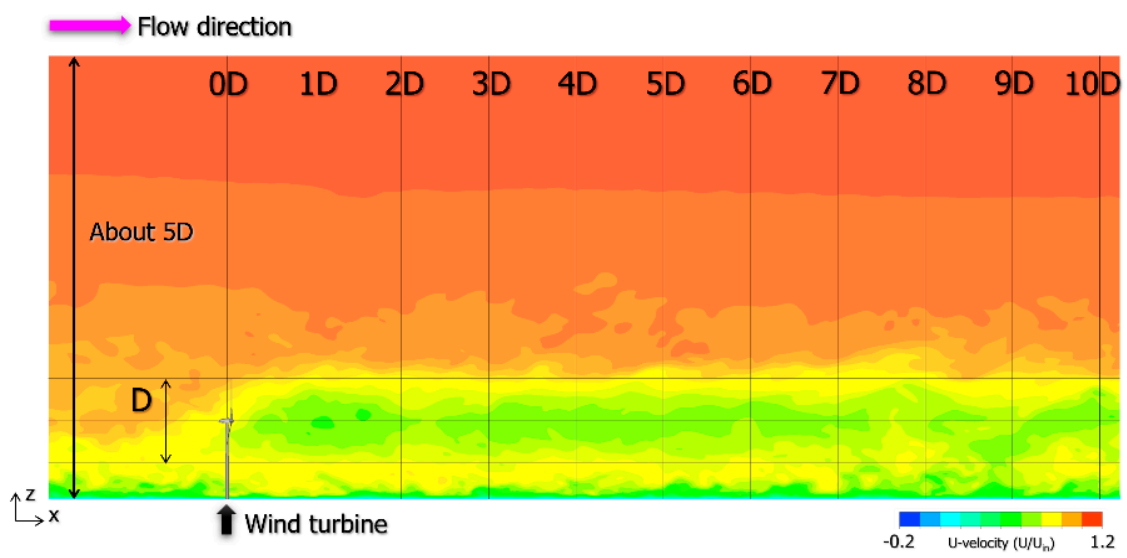

(c)

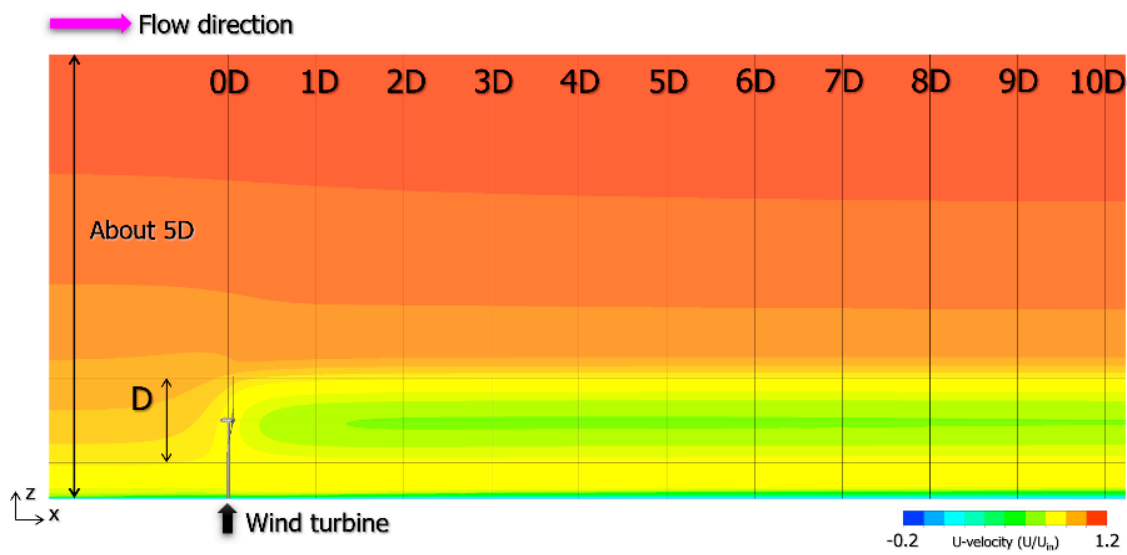

(d)

Figure 21. Side view of spatial distribution of instantaneous U-velocity. (a) Case 1; (b) case 2; (c) case 3 ; and (d) case 4 . 


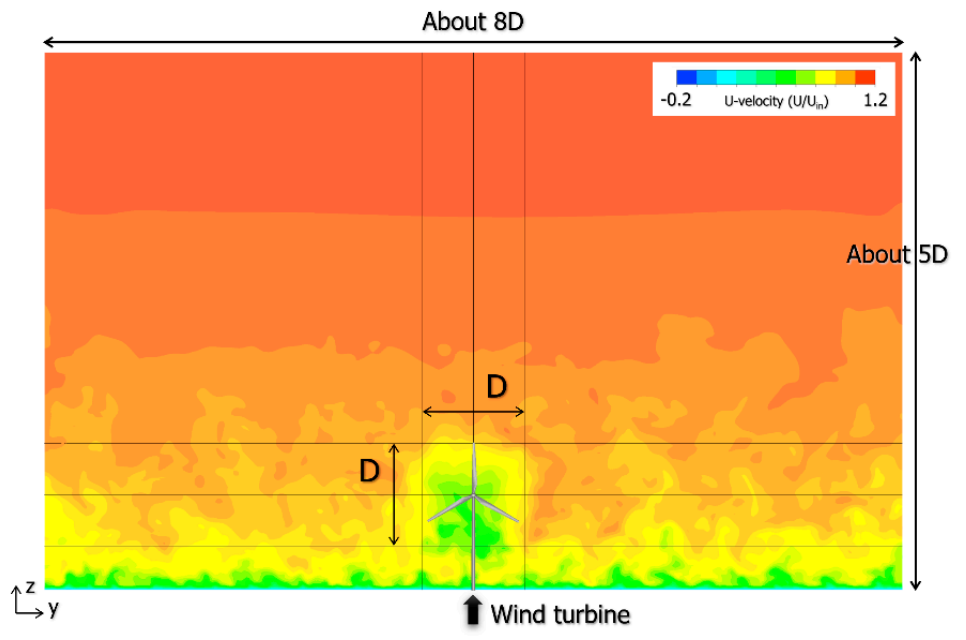

(a)

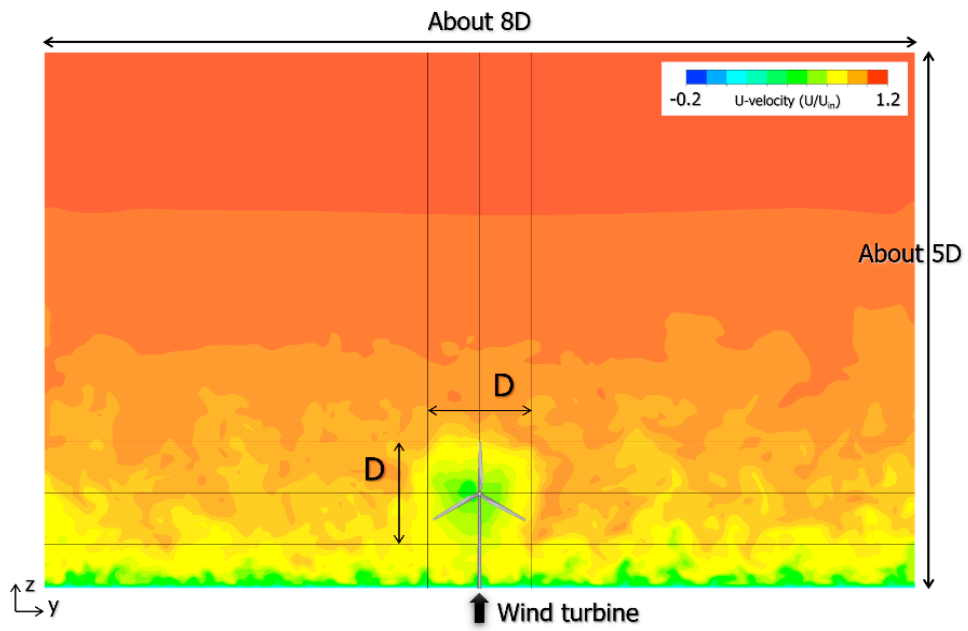

(b)

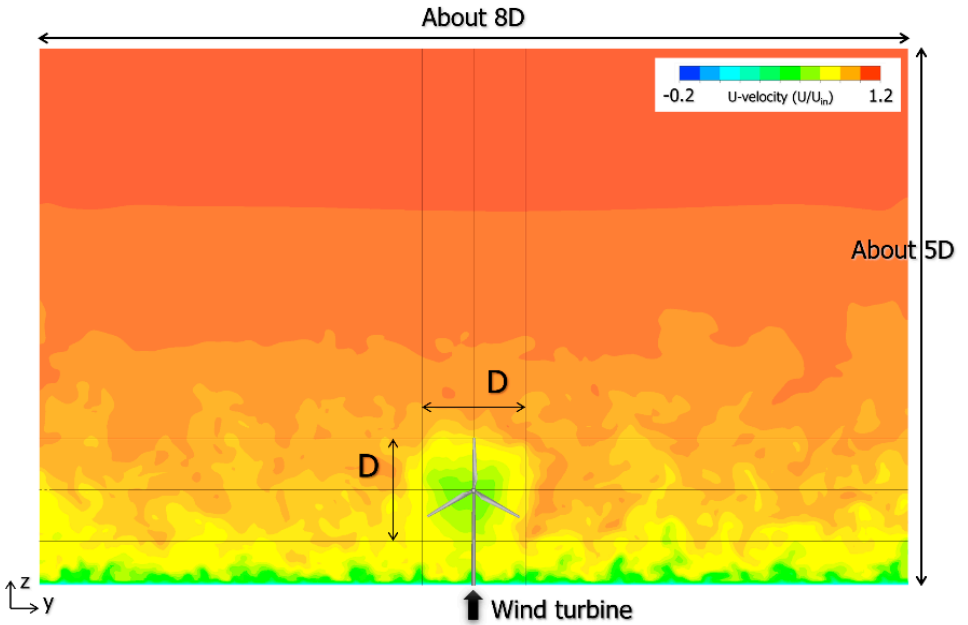

(c)

Figure 22. Cont. 


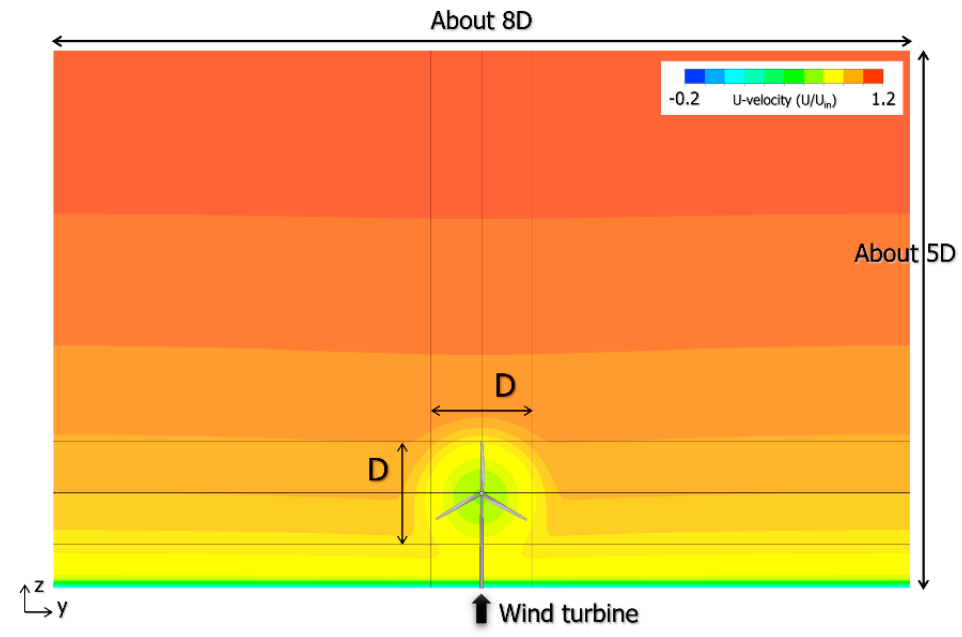

(d)

Figure 22. Rear view of spatial distribution of instantaneous $U$-velocity at $x=3 \mathrm{D}$ (near-wake region). (a) Case 1; (b) case 2; (c) case 3; and (d) case 4.

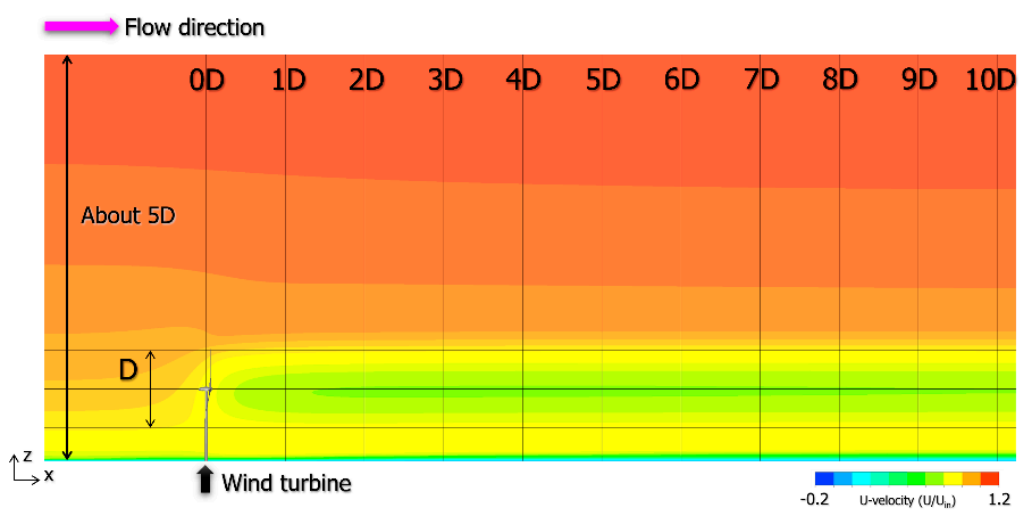

(a)

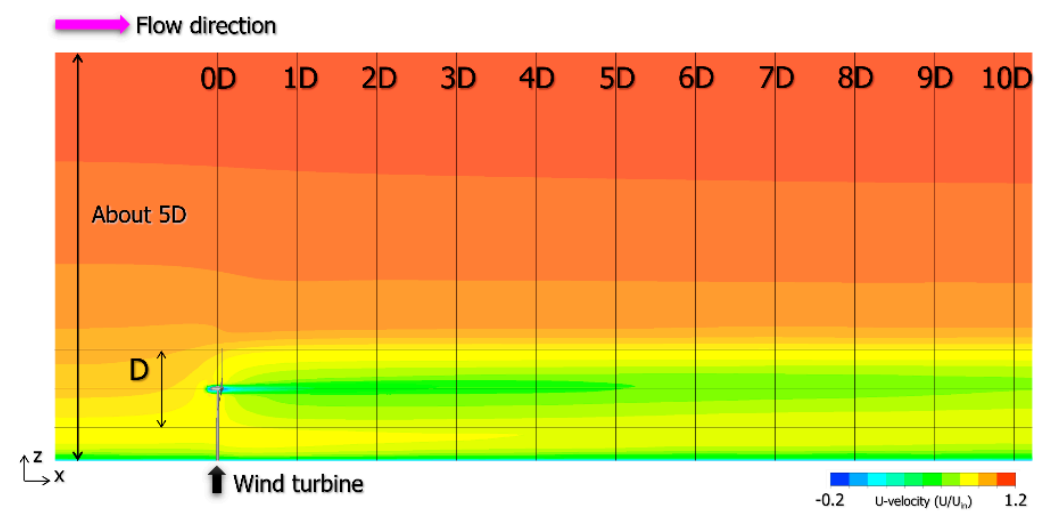

(b)

Figure 23. Cont. 


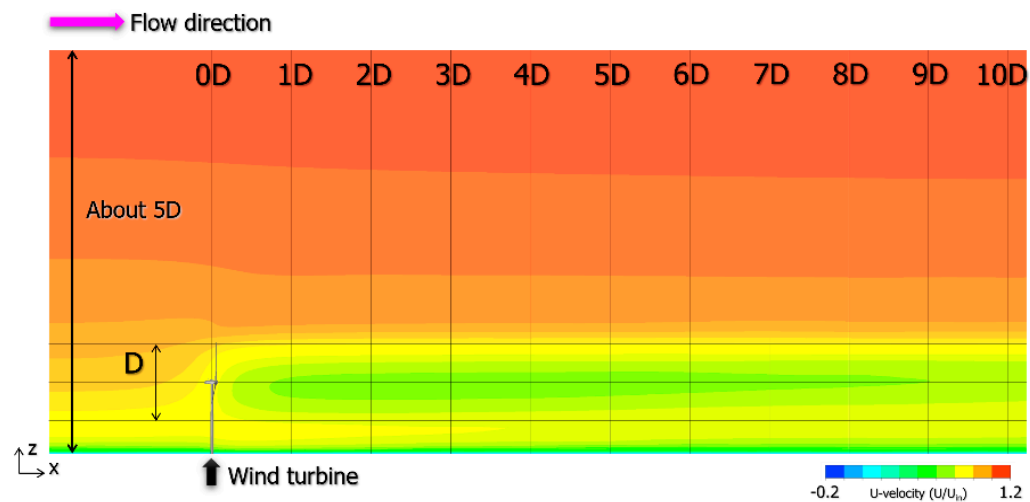

(c)

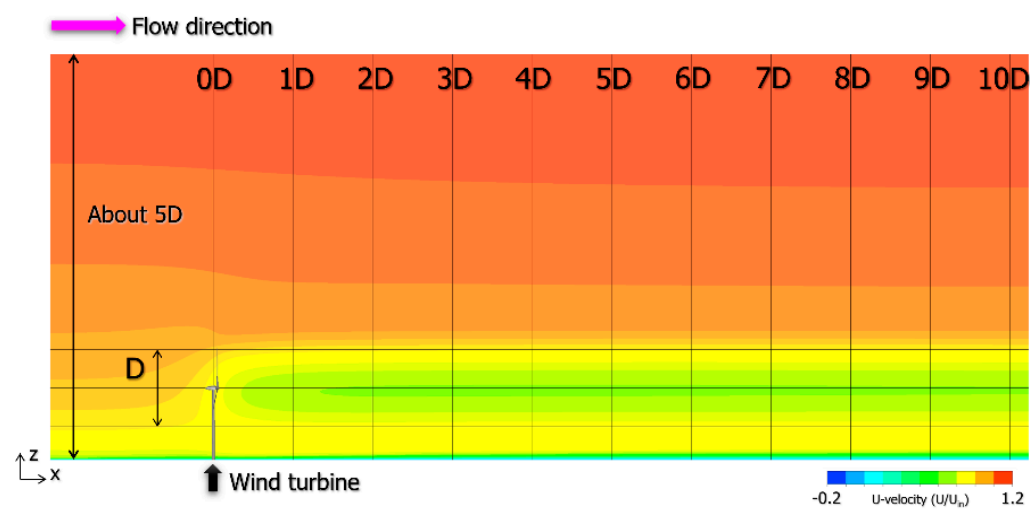

(d)

Figure 23. Side view of spatial distribution of time-averaged U-velocity. (a) Case 1; (b) case 2; (c) case 3 ; and (d) case 4 .

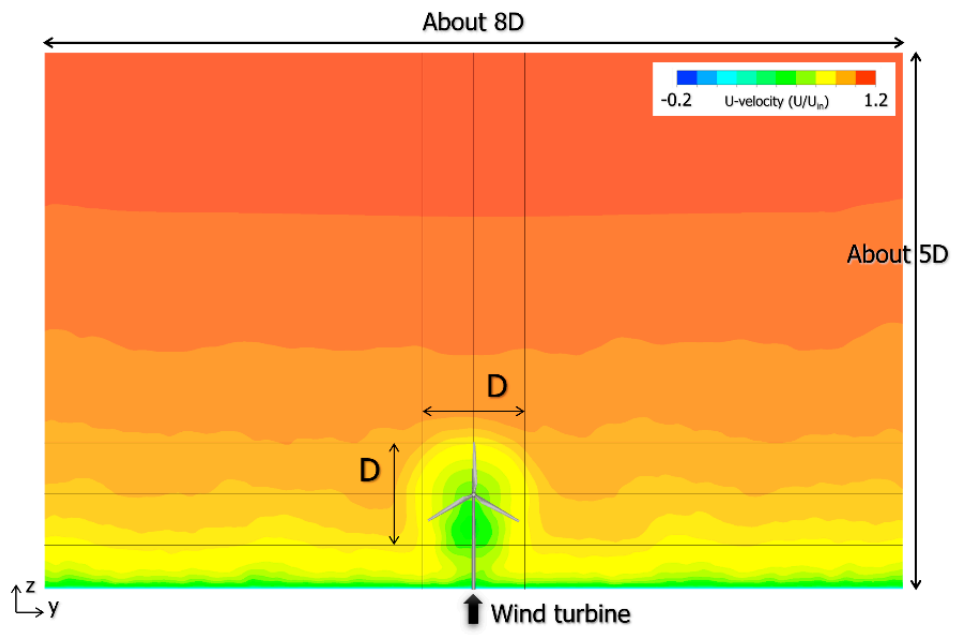

(a)

Figure 24. Cont. 


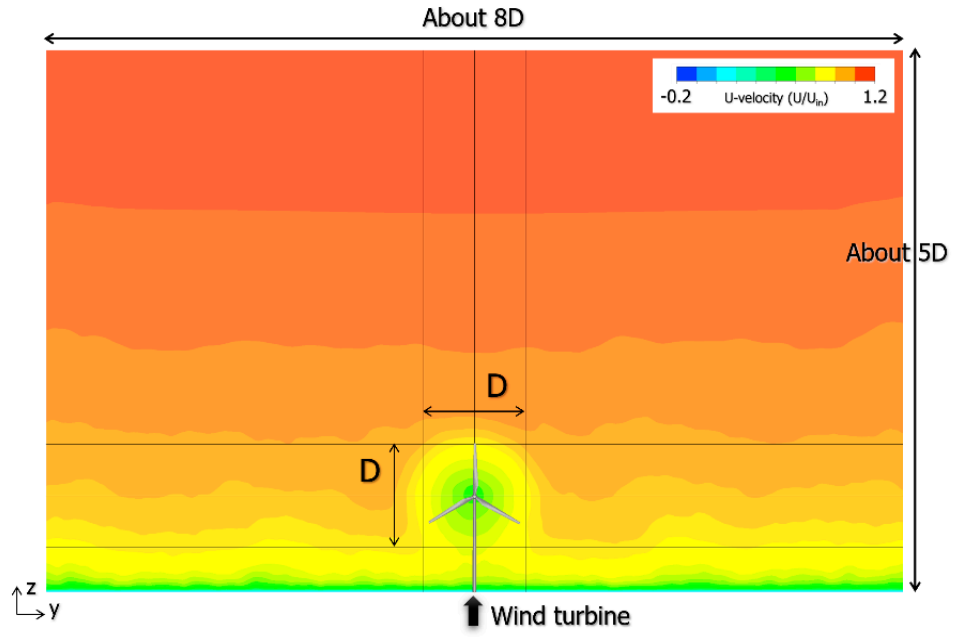

(b)

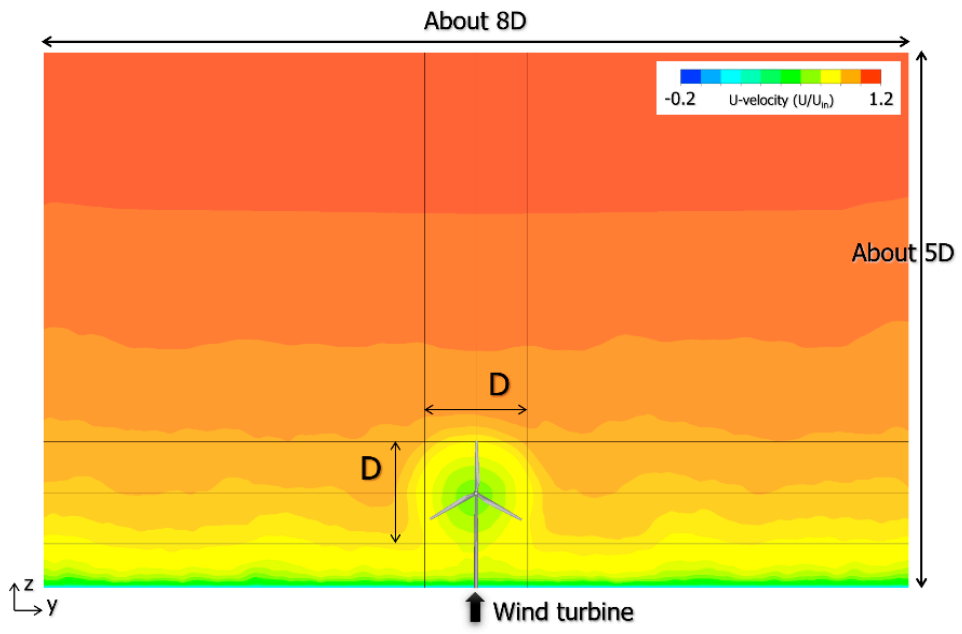

(c)

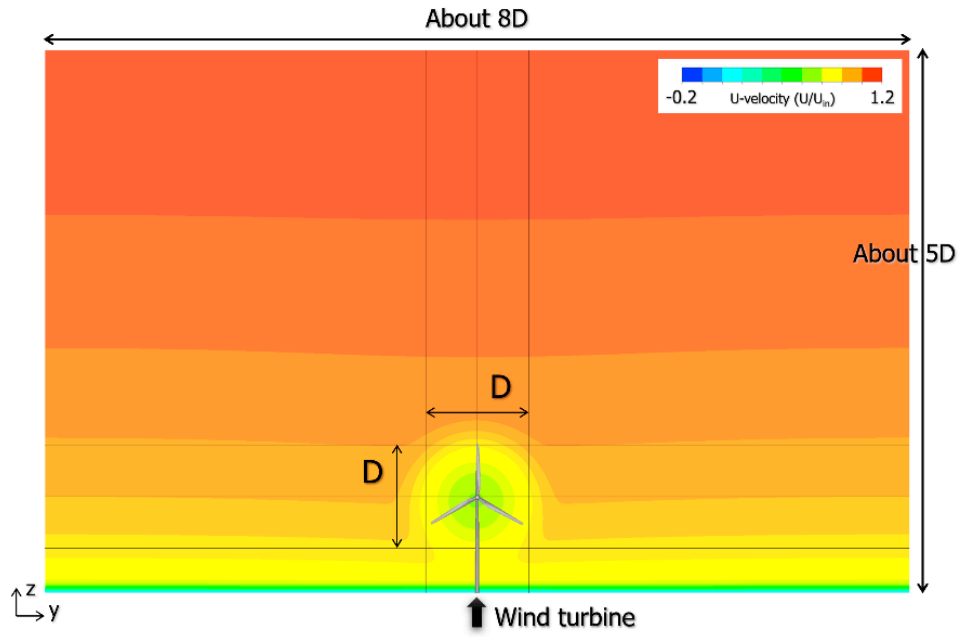

(d)

Figure 24. Rear view of spatial distribution of time-averaged U-velocity at $\mathrm{x}=3 \mathrm{D}$ (near-wake region). (a) Case 1; (b) case 2; (c) case 3; and (d) case 4 . 
Figure 25 shows a comparison of the vertical distribution of the time-averaged Uvelocities at $x=3 \mathrm{D}$ (near-wake region). As already mentioned, the numerical results shown in Figure 25 were created based on the numerical data extracted from the time-averaged flow fields with a sufficiently long dimensionless time of 100 . The figure also shows the range of the wind turbine swept area. The purple symbol is the observation result obtained by the Doppler lidar at a wind speed of $8 \mathrm{~m} / \mathrm{s}$ (wind turbine hub height velocity), which was the target of the numerical simulations using the CFD PD wake model. The inflow profile set in the present simulations is shown by a solid black line for reference. Note first the numerical results for Case 1 shown by the solid green line-those considering all the inflow turbulence, and the separation flows from the nacelle and tower, in addition to the CFD PD wake model applied in the swept area. It is confirmed that the observation data are underestimated at an altitude of $35 \mathrm{~m}$ from the lower end of the wind turbine blade to $78 \mathrm{~m}$ at the wind turbine hub height. This is thought to be due to the effect of the separation flow from the tower in the numerical simulation. Next, note the numerical results for Case 2 shown by the solid blue line. In Case 2, the inflow turbulence and the separation flows from the nacelle are reproduced in addition to the CFD PD wake model without considering the separation flows from the tower. Therefore, the discrepancy between the numerical result and the observation data near the wind turbine hub height at $78 \mathrm{~m}$ is due to the fact that the separation flows from the nacelle were well reproduced in the numerical results. The results for Cases 3 and 4 are notable; the numerical results for both reproduce the observational data obtained using Doppler lidar well over the entire wind turbine swept area. This suggests the following: in practice, when evaluating the mean wind velocity deficit due to wind turbine wakes, the method of applying the CFD PD wake model in the wind turbine swept area is very effective.

Figure 26 shows a comparison of the time-averaged U-velocity space distribution at the wind turbine hub height $(78 \mathrm{~m})$ under a wind speed of $8 \mathrm{~m} / \mathrm{s}$. For reference, the numerical results of the Park model etc. are also shown in this figure. Please note the position $\mathrm{x} / \mathrm{D}=3$ downstream of the wind turbine No.2, which was the focus of this study. It can also be seen that the Park and Ishihara models give a larger velocity loss than the observation data obtained using the Doppler lidar. As mentioned earlier, it can be seen that both Cases 3 and 4 show good agreement with the observational data. However, the CFD PD wake model used in this study cannot reproduce the mean wind velocity deficit due to wind turbine wakes in the entire area downstream of the wind turbine with one parameter, as stated in our published paper [10]. Therefore, it is necessary to set a resistance coefficient $\left(\mathrm{C}_{\mathrm{RC}}\right)$ suitable for the distance from the wind turbine that wind energy/wind farm developers want to evaluate. For example, if wind energy/wind farm developers want to know the exact time-averaged velocity deficit at $x=5 \mathrm{D}$, they should set $C_{R C}$ to 9.0 or 10.0, or if they want to know the exact time-averaged velocity deficit at $x=10 \mathrm{D}$, they should set $C_{R C}$ to 5.0 [10].

Finally, when verifying the behavior of wind turbine wake flows, it may be important to understand its location area. To deal with such a situation, we are developing a method for projecting the vertical flow visualization results of the simulation on Google Earth; the results are shown in Appendix B.

In addition, as explained at the beginning of this paper, the purpose of this study was to accurately predict the mutual interference of wind turbine wakes, especially in a largescale wind farm above the ocean consisting of multiple wind turbine groups. Therefore, in order to examine whether the CFD PD wake model can reproduce the mutual interference of the wind turbine wakes, we assumed a large-scale offshore wind farm consisting of multiple wind turbine groups in the nearshore area; the results are shown in Appendix C. 

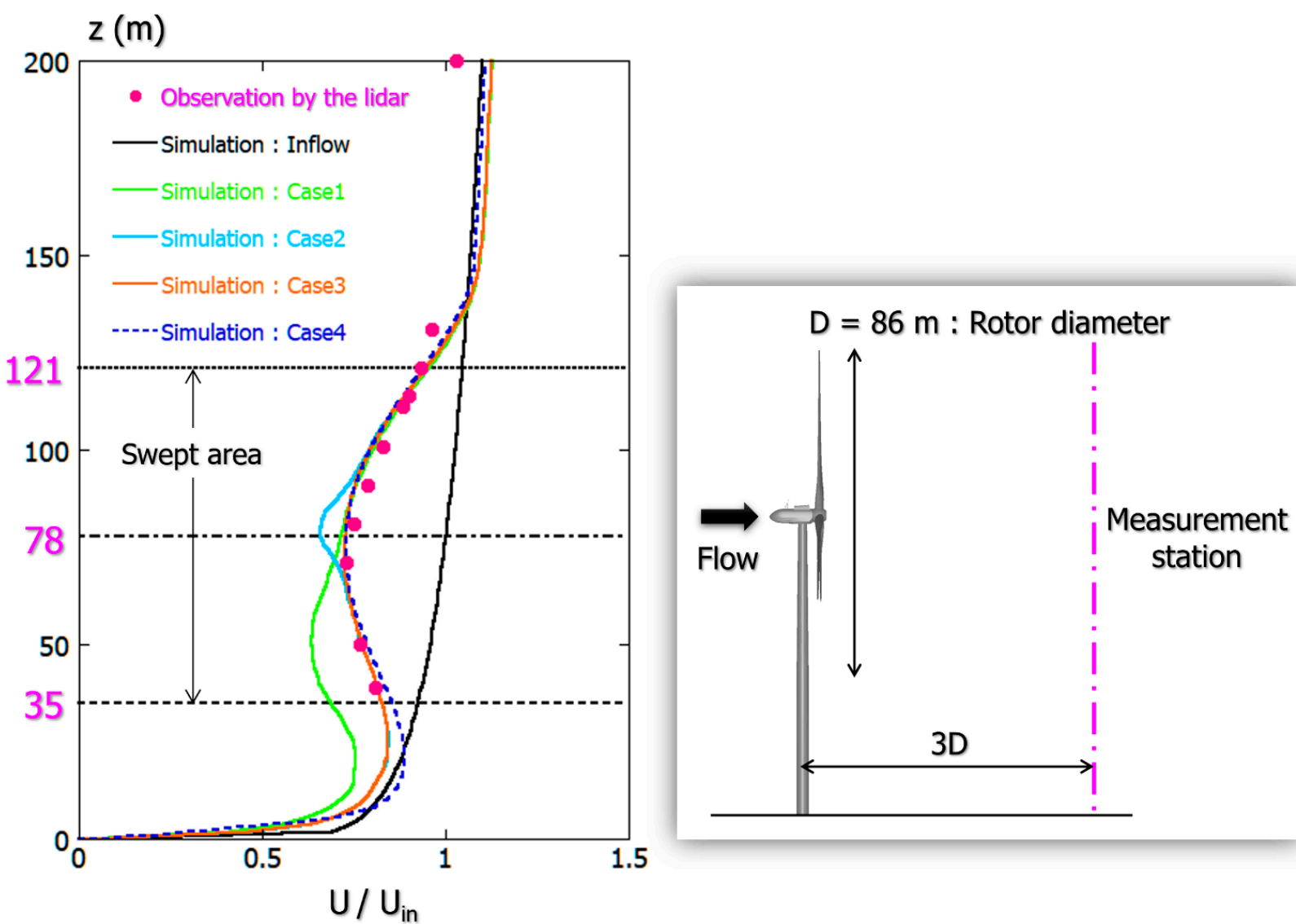

Figure 25. Comparison of vertical distribution of time-averaged U-velocities at the wind speed of $8.0 \mathrm{~m} / \mathrm{s}, \mathrm{x}=3 \mathrm{D}$ (nearwake region).
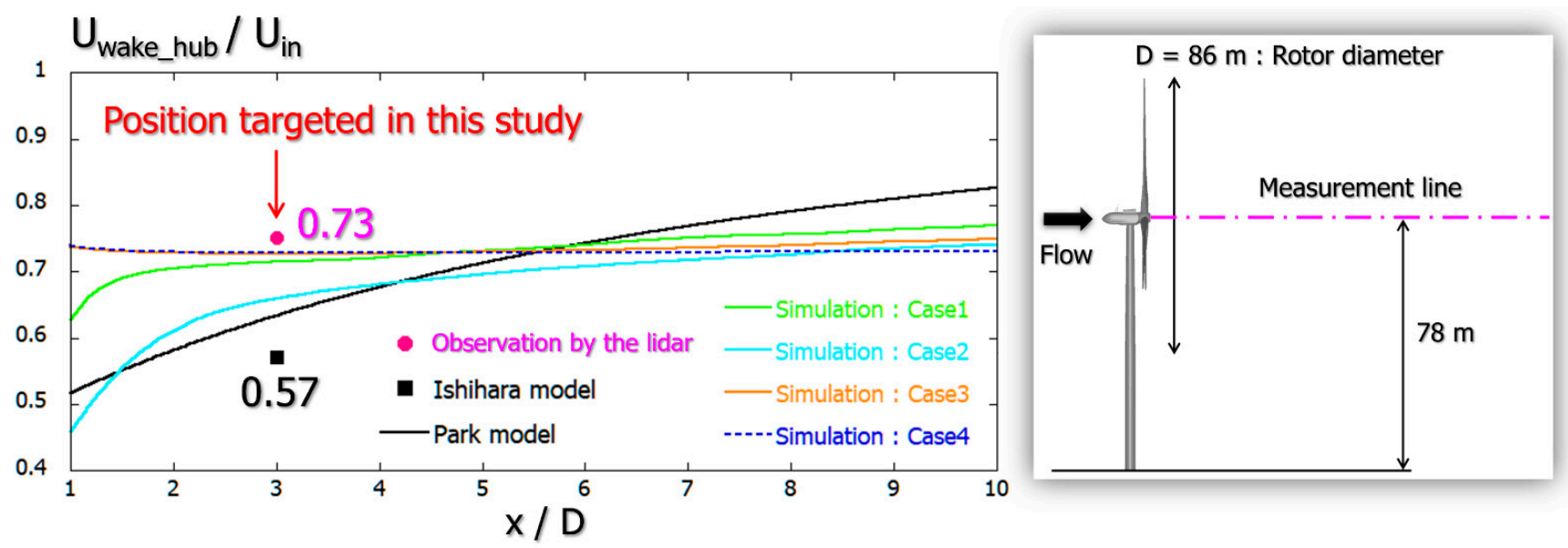

Figure 26. Comparison of time-averaged U-velocity space distribution at the wind turbine hub height $(78 \mathrm{~m})$ under the wind speed of $8.0 \mathrm{~m} / \mathrm{s}$. 


\section{Conclusions}

In the present study, the validity of the CFD PD wake model was verified by the wake flows of a $2 \mathrm{MW}$-class downwind turbine. We first clarified the airflow characteristics of the wind turbine wake flows using a vertically profiling remote sensing wind measurement device (lidar) for the wind turbines installed at the point where the sea is just in front of the wind turbines. A ground-based continuous-wave $(\mathrm{CW})$, conically scanning wind lidar system was used. We paid particular attention to the behavior of the wind turbine near-wakes, which are about three times the diameter of the wind turbine's blade. It was apparent that the influence of the wind turbine wake, that is, the amount of wake loss (wind velocity deficit) is extremely large in the wind speed range of $6.0-10.0 \mathrm{~m} / \mathrm{s}$. Furthermore, it was shown that the wake loss (wind velocity deficit) was almost the same at wind speeds of $6.0-10.0 \mathrm{~m} / \mathrm{s}$. It was also shown, again, that these results correspond to the distribution of the thrust coefficient of the wind turbine. Currently, many bottom-mounted offshore wind farms are planned for the coastal areas of Japan, where wind speeds of $6.0-10.0 \mathrm{~m} / \mathrm{s}$ are extremely frequent; in other words, wind speeds of $6.0-10.0 \mathrm{~m} / \mathrm{s}$ are highly relevant for the realization of bottom-mounted offshore wind farms. Therefore, in the evaluation of the feasibility of bottom-mounted offshore wind farms, strict evaluation at a wind speed of $6.0-10.0 \mathrm{~m} / \mathrm{s}$ is important; this range was selected in this study for reproducing the behavior of the wind turbine wakes with the CFD PD wake model. Targeting the vertical wind speed distribution in the near-wake region acquired in the lidar, we tuned the model parameters of the CFD PD wake model and considered the numerical results, including those from the conventional engineering wake models. A large parallel computation was performed using a vector supercomputer, showing that, in practice, when evaluating the mean wind velocity deficit due to wind turbine wakes, the method of applying the CFD PD wake model in the wind turbine swept area is very effective.

Author Contributions: Project administration, conceptualization and methodology, T.U.; data curation, T.Y., M.I. and Y.T. And, all authors prepared the manuscript. All authors have read and agreed to the published version of the manuscript.

Funding: This research received no external funding.

Institutional Review Board Statement: Not applicable.

Informed Consent Statement: Not applicable.

Data Availability Statement: The data used to support the findings of this study are available from the corresponding author upon request.

Acknowledgments: This research was carried out as a joint effort between Toshiba Energy Systems Co., Ltd. and Hitachi Zosen Corporation (Principal Investigator: Takanori Uchida), ongoing since April 2018. We would like to express our gratitude to the people concerned. Company, product and service names appearing in this publication include those that are trademarks or registered trademarks of their respective companies.

Conflicts of Interest: The authors declare no conflict of interest.

\section{Appendix A. Arrangement of Park Model Formulation}

Figure A1 shows a schematic of the wake deficit and expansion by the Park model, which is formulated as described below based on that figure. 


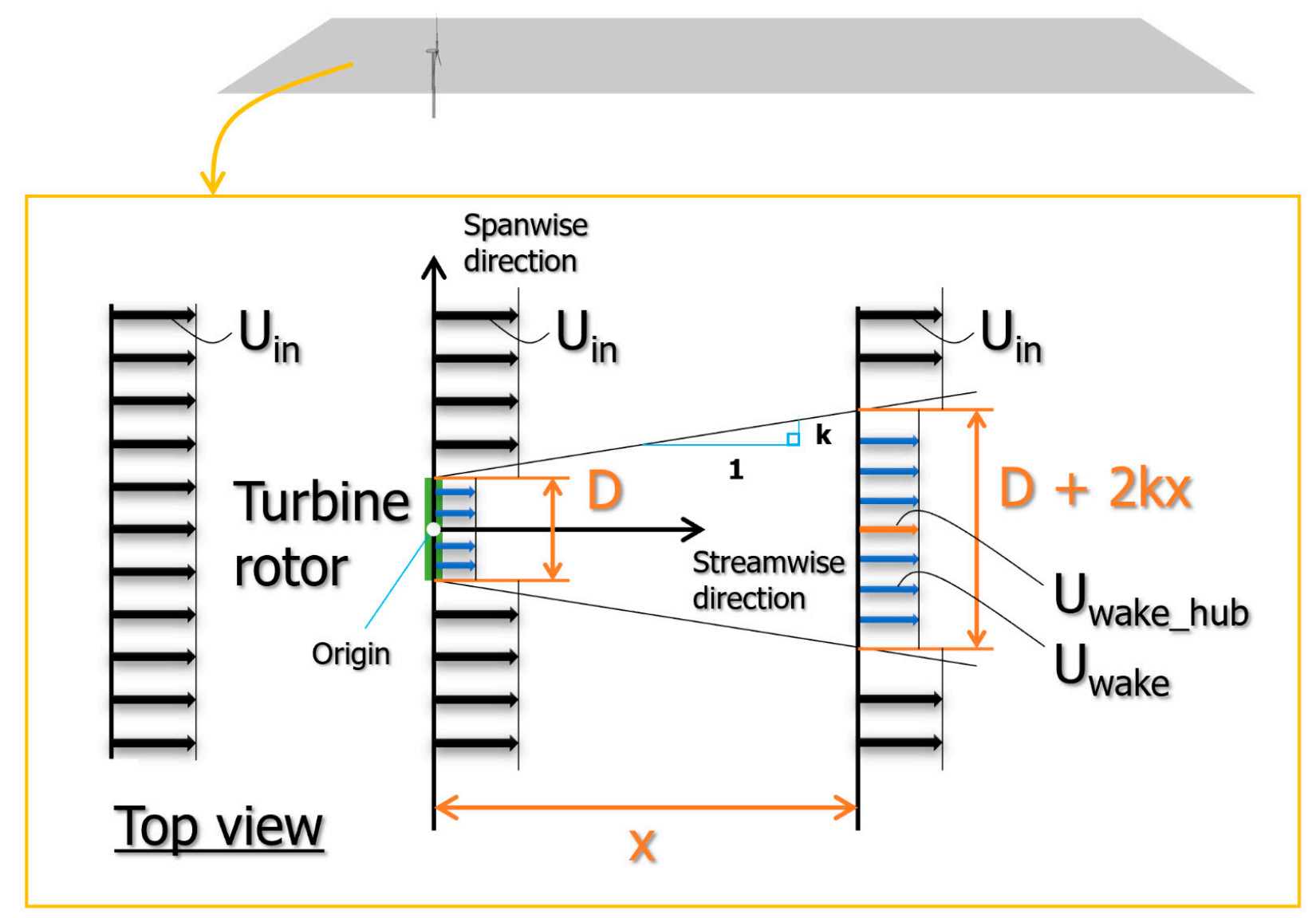

Figure A1. Schematic of wake deficit and expansion by the Park model.

$$
\mathrm{U}_{\text {wake }}=\mathrm{U}_{\text {in }}\left[1-\frac{1-\sqrt{1-\mathrm{C}_{\mathrm{t}}}}{\left(1+\frac{2 \cdot \mathrm{k} \cdot \mathrm{x}}{\mathrm{D}}\right)^{2}}\right]
$$

Here, each variable in the equation is as follows:

$\mathrm{U}_{\text {in }}$ is the (hub height) inflow wind speed;

$\mathrm{U}_{\mathrm{wake}}$ is the hub height wind speed downstream of the wind turbine at a distance $\mathrm{x}$;

$\mathrm{C}_{\mathrm{t}}$ is the thrust coefficient;

$\mathrm{D}$ is the rotor diameter;

$\mathrm{k}$ is the wake decay constant.

\section{Appendix B. Examination of Effectiveness of Flow Visualization on "Google Earth"}

We also developed technology to project the numerical results obtained with the CFD PD wake model onto "Google Earth". Figure A2 shows the results of projecting the calculation results obtained with the CFD PD wake model on "Google Earth". Projecting the numerical results onto a common platform on the Internet that is easily accessible by everyone is useful for consensus building. 


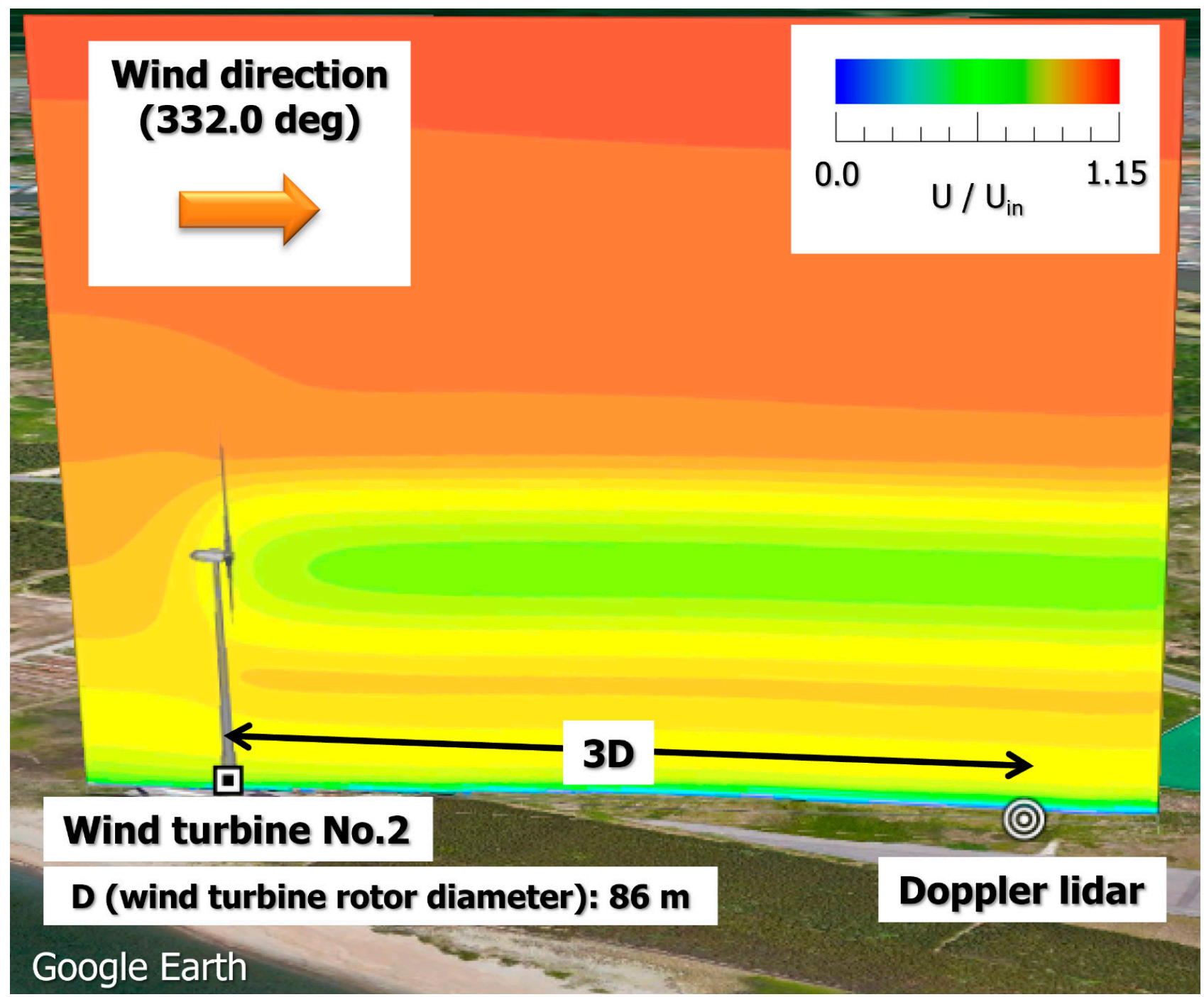

Figure A2. Result of projecting the simulation result obtained with the computational fluid dynamics porous disk (CFD PD) wake model on "Google Earth".

Appendix C. Desktop Study of a Virtual Offshore Wind Farm in the Coastal Area Using the CFD PD Wake Model

We conducted a desk study of a virtual offshore wind farm consisting of 18 wind turbines in the coastal area using the CFD PD wake model. Figure A3 shows the obtained numerical results. Wake flows are formed from each wind turbine, and their interference with one another in a complicated manner is clearly reproduced. 


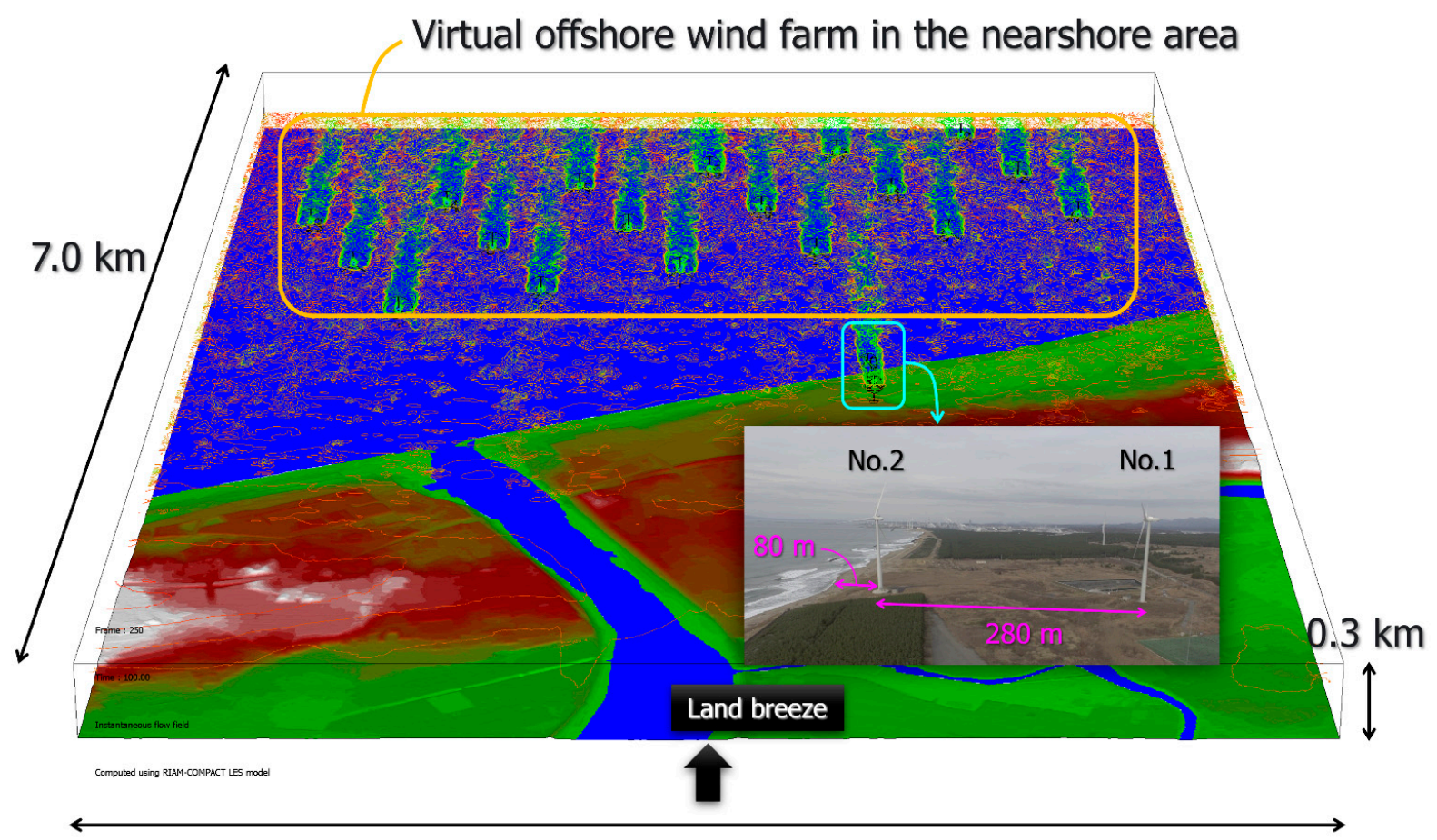

$4.5 \mathrm{~km}$

Figure A3. Numerical investigation of a virtual offshore wind farm in the coastal area near the Omonogawa Wind Power Station using the CFD PD wake model.

\section{References}

1. Sumner, J.; Watters, C.S.; Masson, C. CFD in Wind Energy: The Virtual, Multiscale Wind Tunnel. Energies 2010, 3, 989-1013. [CrossRef]

2. Hewitt, S.; Margetts, L.; Revell, A. Building a Digital Wind Farm. Arch. Comput. Methods Eng. 2018, 25, 879-899. [CrossRef] [PubMed]

3. Porté-Agel, F.; Bastankhah, M.; Shamsoddin, S. Wind-Turbine and Wind-Farm Flows: A Review. Bound. Layer Meteorol 2020, 174, 1-59. [CrossRef] [PubMed]

4. Dasari, T.; Wu, Y.; Liu, Y.; Hong, J. Near-wake behaviour of a utility-scale wind turbine. J. Fluid Mech. 2019, 859, 204-246. [CrossRef]

5. Bossuyt, J.; Howland, M.F.; Meneveau, C.; Meyers, J. Measurement of unsteady loading and power output variability in a micro wind farm model in a wind tunnel. Exp. Fluids 2017, 58,1-17. [CrossRef]

6. Ansys CFX. Turbomachinery CFD Software. Available online: https://www.ansys.com/products/fluids/ansys-cfx (accessed on 1 March 2020).

7. Simcenter STAR-CCM+. Available online: https://www.plm.automation.siemens.com/global/de/products/simcenter/STARCCM.html (accessed on 1 March 2020).

8. Jensen, N.O. A Note on Wind Generator Interaction; Technical Report Risoe-M-2411(EN); Risø National Laboratory: Roskilde, Denmark, 1983.

9. Katic, I.; Højstrup, J.; Jensen, N.O. A simple model for cluster efficiency. In Proceedings of the European Wind Energy Association Conference \& Exhibition (EWEC'86), Rome, Italy, 6-8 October 1986; Volume 1, pp. 407-410.

10. Uchida, T.; Taniyama, Y.; Fukatani, Y.; Nakano, M.; Bai, Z.; Yoshida, T.; Inui, M. A New Wind Turbine CFD Modeling Method Based on a Porous Disk Approach for Practical Wind Farm Design. Energies 2020, 13, 3197. [CrossRef]

11. Scientific, C. Finance Grade Performance, ZephIR 300; Technical Report; Campbell Scientific, Inc.: Edmonton, AB, Canada, 2016.

12. Kogaki, T.; Sakurai, K.; Shimada, S.; Kawabata, H.; Otake, Y.; Kondo, K.; Fujita, E. Field Measurements of Wind Characteristics Using LiDAR on a Wind Farm with Downwind Turbines Installed in a Complex Terrain Region. Energies 2020, 13, 5135. [CrossRef]

13. Ishihara, T.; Qian, G. Numerical and Analytical Study of Wind Turbine Wakes. In Proceedings of the National Symposium on Wind Engineering, Tokyo, Japan, 5-7 December 2016; Volume 24, pp. 151-156.

14. Uchida, T.; Araya, R. Practical Applications of the Large-Eddy Simulation Technique for Wind Environment Assessment around New National Stadium, Japan (Tokyo Olympic Stadium). Open J. Fluid Dyn. 2019, 9, 269. [CrossRef]

15. Inagaki, M.; Kondoh, T.; Nagano, Y. A Mixed-Time-Scale SGS Model with Fixed Model-Parameters for Practical LES. ASME J. Fluids Eng. 2005, 127, 1-13. [CrossRef] 
16. Uchida, T.; Kawashima, Y. New Assessment Scales for Evaluating the Degree of Risk of Wind Turbine Blade Damage Caused by Terrain-Induced Turbulence. Energies 2019, 12, 2624. [CrossRef]

17. Uchida, T.; Takakuwa, S. A Large-Eddy Simulation-Based Assessment of the Risk of Wind Turbine Failures Due to Terrain-Induced Turbulence over a Wind Farm in Complex Terrain. Energies 2019, 12, 1925. [CrossRef]

18. Lund, T.S.; Wu, X.; Squires, K.D. Generation of Turbulent Inflow Data for Spatially-Developing Boundary Layer Simulations. J. Comput. Phys. 1998, 140, 233-258. [CrossRef] 